\title{
Article
}

\section{Methodological considerations of integrating portable digital technologies in the analysis and management of complex superimposed Californian pictographs: From spectroscopy and spectral imaging to 3-D scanning}

Robinson, David Wayne, Baker, Matthew J., Bedford, Clare, Perry, Jennifer, Wienhold, Michelle, Bernard, Julienne, Reeves, Dan, Kotoula, Eleni, Gandy, Devlin and Miles, James

Available at http://clok.uclan.ac.uk/12308/

Robinson, David Wayne ORCID: 0000-0002-0729-5011, Baker, Matthew J., Bedford, Clare, Perry, Jennifer, Wienhold, Michelle, Bernard, Julienne, Reeves, Dan, Kotoula, Eleni, Gandy, Devlin et al (2015) Methodological considerations of integrating portable digital technologies in the analysis and management of complex superimposed Californian pictographs: From spectroscopy and spectral imaging to 3-D scanning. Digital Applications in Archaeology and Cultural Heritage, 2 (2-3). pp. 166-180. ISSN 22120548

It is advisable to refer to the publisher's version if you intend to cite from the work. http://dx.doi.org/10.1016/j.daach.2015.06.001

For more information about UCLan's research in this area go to http://www.uclan.ac.uk/researchgroups/ and search for <name of research Group>.

For information about Research generally at UCLan please go to http://www.uclan.ac.uk/research/

All outputs in CLoK are protected by Intellectual Property Rights law, including Copyright law. Copyright, IPR and Moral Rights for the works on this site are retained by the individual authors and/or other copyright owners. Terms and conditions for use of this material are defined in the policies page.

CLoK

Central Lancashire online Knowledge www.clok.uclan.ac.uk

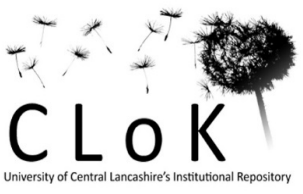




\section{CLoK}

Central Lancashire online Knowledge www.clok.uclan.ac.uk 
Methodological Considerations of Integrating Portable Digital Technologies in the Analysis and Management of Complex Superimposed Californian Pictographs: from Spectroscopy and Spectral Imaging to 3-D scanning

David Robinson (University of Central Lancashire); Matthew J. Baker (University of Strathclyde); Clare Bedford (University of Central Lancashire); Jennifer Perry (California State University, Channel Islands); Michelle Wienhold (University of Iowa); Julienne Bernard (East Los Angeles College); Dan Reeves (Rock Art Documentation Group); Eleni Kotoula (University of Southampton); Devlin Gandy (University of California, Berkeley); James Miles (Archaeovision).

\begin{abstract}
:
How can the utilization of newly developed advanced portable technologies give us greater understandings of the most complex of prehistoric rock art? This is the questions driving The Gordian Knot project analysing the polychrome Californian site known as Pleito. New small transportable devices allow detailed on-site analyses of rock art. These non-destructive portable technologies can use X-ray and Raman technology to determine the chemical elements used to make the pigment that makes the painting; they can use imaging techniques such as Highlight Reflective Transformation Imaging and dStretch@ to enhance their visibility; they can use digital imagery to disentangle complex superimposed paintings; and they can use portable laser instruments to analyse the micro-topography of the rock surface and integrate these technologies into a 3-D environment. This paper outlines a robust methodology and preliminary results to show how an integration of different portable technologies can serve rock art research and management.
\end{abstract}

\title{
1. Introduction
}

How can utilizing newly developed advanced portable technologies give us greater understandings of the most complex prehistoric rock art found across the globe? This is the central research question driving our research under the title of 'The Gordian Knot'. Rock art was part of the repertoire of the earliest anatomically modern humans (Pike et al 2012), was subsequently made in every time period, and is found on every continent save Antarctica: understanding rock art thus is fundamental to understanding human environmental and social 
interactions worldwide. Rock art is studied by researchers across disciplinary spectrums, so developing techniques to better analyse rock art will clearly benefit researchers across multiple disciplines. As Chippindale and Nash (2004: 7) succinctly point out, rock art's great strength is the fact that it is fixed in place. However, this strength is ironically the central problem confronting rock art research: its lack of portability limits laboratory analyses to understand the material component comprising the art, thereby limiting interpretation of the art. Fortunately, recent advances in portable technologies have greatly increased the ability to analyse in situ rock art. This project aims to directly tackle the problem of fixity with the question posed above: we aim to develop a methodology that integrates new but proven portable technologies to analyse the most important, compelling, and complex rock-art confronting researchers everywhere: that made up of multiple superimposed paintings and utilizing multiple colours. Such an approach ultimately allows a far deeper probing of the materiality of pigments comprising the paintings than previously possible. The use of pigments far predates any known rock art itself (Barham 2002), and has been a fundamental form of material culture ever since. The application of pigments on artefacts, walls, canvases, rock and other surfaces is of high interest across a wide multiplicity of disciplines, so scientific studies of pigments that link interpretative approaches will have wide reaching applicability. Research here thus sets out to establish a methodology that allows for deeper quantitative and qualitative interpretations of complex surface-applied pigments not only on rock, but other surfaces across disciplines.

To achieve this requires a focussed study on an accessible, world class, highly complex painted site. Fortunately, we have access to such a site. The site is called Pleito, located on the Wind Wolves Preserve in South-Central California in an area attributed to the native group known as the Emigdiano Chumash. Campbell Grant (1978: 532) described the site as the "finest example of prehistoric rock art in the United States." This is probably because the pictographs at Pleito have one of the widest colour palettes of any site in the world, with multiple variants of red, black, white, cream, yellow, orange, green, and blue (see Bury et. al 2003). Within the Main Cave of the site, there are 12 polychrome panels comprising hundreds of individual elements (Figure 1). These panels also likely have the greatest intensity of superimposed painting of any other pictograph site on the North American continent.

Figure 1. View of the mouth of the Main Cave, Pleito, California. Photo by David Robinson. 
The conjoined Panels A/G/H are contiguous; during documentation of the site in 2003, Dan Reeves called these panels the 'Gordian Knot' due to the sheer complexity of paintings located there (Figure 2). In total, the Gordian Knot paintings forms one of the most complex prehistoric panels found anywhere in the world.

Figure 2. The conjoined panels of A/G/H, known as the 'Gordian Knot'. Photo by David Robinson

This site is thus ideal for applying, and integrating, a range of portable technologies including portable X-Ray Fluorescence, portable Raman Spectroscopy, portable digital laser scanning, dStretch $\odot$, and Highlight Reflectance Transformation Imaging. We therefore have launched a new AHRC funded project called "Unravelling the Gordian Knot". The Gordian Knot project is a collaboration between academic researchers at the University of Central Lancashire, University of Strathclyde, California State University, Channel Islands, plus professional collaborators such as the Rock Art Documentation Group based in Santa Barbara and B\&W Tech based in New Jersey as well as the Wildlands Conservancy who are the landowners of the Wind Wolves Preserve. The project sets out to disentangle the superimposed painted events using imaging techniques, use a technique called Layer Separation to create a Harris Matrix for all the panels, to analyse the material components used in the making of the pigments through seriated time. An experimental study will complement this research by providing comparative data to interpret some of the spectral results. The project aims to establish a replicable and robust methodology of integrating portable technologies that can be utilized in the analysis of similarly complex superimpositions anywhere in the world. In turn, the data will allow deep and nuanced questions to be addressed concerning pigment recipes and change through time while opening new theoretical vistas to rethink ethnographic and other theoretical notions of pigment as a form of material culture. Furthermore, located on the Wind Wolves Preserve in the heart of South-Central California near the large urban population centres, the site is continually under pressure from human visitation, either in the form of research, tours, or even trespass. The project aims to provide information to the Preserve for its management of the site, as well as create a website which may be used to provide an alternative means of experiencing the site as a complement or alternative to actual site visitation. The Gordian Knot project will conduct this research over the next several years. This paper details the methodology behind 
this project, and presents the initial findings from a pilot project, including a case study from panel $\mathrm{C}$ in the Main Cave.

\section{Background and Methodology}

Previous work has focussed on Geographic Information Systems approaches to Pleito and its relationship to land-use, viewshed, and movement (Robinson 2006; Robinson 2010a; Wienhold 2014), issues of pigment composition (Lee 1979; Reeves et al. 2009; Scott et al 2002) or interpretative approaches considering indigenous ethnography and ontology (Robinson 2007; 2010b; 2013a; 2013b). The site is located on either side of a perennial stream in a rich riparian environment with oak woodlands in all directions (Figure 3).

Figure 3. Topographic map of Pleito.

The sandstone formations on the eastern side of the creek contain at least five pictograph loci, plus nine bedrock mortar stations with 61 bedrock mortars, and over 100 cupules (Robinson 2006: 219). Middens are located on terraces on either side of the stream. Grasse (2005) has conducted excavations of the Lower Midden in front of a rock art locus known as Boulder Cave: the midden is over 2 meters in depth with finds of lithic debitage, projectile points, ground stone material, charcoal, animal bone, ochre, and beads: various strands of dating evidence suggest occupation since at least 2000 years ago with intermittent occupation until the late AD1800s. With its abundant bedrock mortars, midden material, and paintings, Pleito is a premier example of a regional type site known as pictograph K-locales (Robinson 2010a). As a key location in the landscape, these sites are strategically situated for access to fauna and faunal resources fundamental to food acquisition and the collection of material as raw resources for a range of different forms of perishable material culture. The archaeological evidence in total shows that a wide range of activities occurred near and oftentimes immediately adjacent to the paintings, thus establishing a highly public context for the visual consumption of the art. Robinson (2007; 2010a; 2010b; 2013a; 2013b) has argued that the rock art is thus imbricated within internal Chumash societal relationships and likely played a fundamental role in strategies of ideology and legitimation within this complex hunter-gatherer society (see Robinson 2012).

In 2003, Bury et al. published a documentation and conditional assessment of the rock art at Pleito. In that report, they identified the extreme fragility of the rock paintings at Pleito on the friable sandstone surface, including high risk portions of panels that are undergoing 
natural processes of blind detachment whereby the sandstone behind the paintings erode away. Visitation to the site for research or public educational engagement has taken place since that time within the context of the Preserves mission statement to educate the public. These activities of course potentially present risks to the integrity of this world class prehistoric art. Now, almost 15 years since that report, it therefore is timely that our project takes place to analyse the paintings as fully as currently possible, compare the paintings now to the baseline established in 2003, and to provide information to the land owners so that they can make informed decisions

\subsection{Portable X-Ray Fluorescence}

Recent advances in portable XRF and Raman technologies have shown remarkable efficacy in analysing in-situ pigments (Olivares et al. 2013; Tournie et al 2010). Bedford's research (2013; Bedford et. al 2014) shows the applicability of pXRF in the analysis of pictographs at sites on the Wind Wolves Preserve near to Pleito. Olivares et al (2013) and Pitarch et al (2014) have successfully combined pXRF with pRaman in their study of monochrome pictographs. Thus, incremental work over the past few years shows that XRF and Raman portable technologies can differentiate different chemical compositions of painted rock art. However, work has not yet focussed on complex superimposed sites. Studies rarely collate comparison spectra libraries on pigment samples from quarries, archaeological deposits, or experimental means to enable comparisons between in situ pigments in rock art with potential sources and associated deposits. This is exacerbated by a wider lack of understanding of how usage of different raw materials and techniques of processing changed through time.

An initial programme of research was undertaken to assess the viability of utilizing pXRF on sandstone formations such as that at Pleito by investigating nearby pictograph sites on similar formations. XRF devices work by temporarily irradiating samples using X-Ray radiation, causing the chemical elements within them to fluoresce. Each chemical element has its own characteristic radiation and can therefore be identified by the detector within the device. XRF instruments are either Wavelength dispersive (WXRF) or Energy dispersive (EDXRF). WXRF detects elements within a selected range of wavelengths, which are selected using prisms within the instrument, whereas EDXRF can detect elements across the whole range of the instrument by measuring the energy level of the emissions, but is slightly less accurate. There are many lab based XRF devices which can analyse samples once they are ground into powder. Such preparation is often necessary for chemical analysis using 
laboratory instruments but it is not needed when using portable XRF. As no sample preparation is needed, portable XRF can be used to examine in situ archaeological remains and it does not cause any damage to the materials being examined.

Previous work on the Wind Wolves Preserve using pXRF looked at five pictograph sites: Pinwheel, Pond, Three Springs, Los Lobos and Santiago using a handheld or portable XRF spectrometer (Bedford 2013; Bedford et al. 2014). While these sites do not have the same degree of complexity or superimposition as Pleito, they were chosen because each has been excavated as part of a long term project to investigate the occupational character of South-Central Californian pictograph sites (see Robinson et al. 2010; Robinson and Sturt 2008). Readings were taken from each rock art element and background readings were taken from the rock around each of these. In total between 5 and 10 readings were taken from each rock art element as shown in the table below.

\begin{tabular}{lllll}
\hline Site & No. Panels & No. Readings & No. Elements & $\begin{array}{l}\text { Average } \\
\text { readings per } \\
\text { element }\end{array}$ \\
\hline Pinwheel & 2 & & & $\mathbf{6 . 5}$ \\
Three Springs & 3 & 59 & 9 & $\mathbf{1 0 . 5}$ \\
Pond & 3 & 29 & 6 & $\mathbf{5 . 8}$ \\
Los Lobos & 3 & 119 & 5 & $\mathbf{6 . 6}$ \\
Santiago & 2 & 141 & 18 & $\mathbf{7 . 4}$ \\
Total & $\mathbf{1 3}$ & $\mathbf{4 1 1}$ & 19 & $\mathbf{7 . 2}$ \\
\hline
\end{tabular}

The analysis was undertaken using a Bruker Tracer III handheld X-Ray fluorescence spectrometer. S1PXRF software was used to gather the spectra, the device was set at $40 \mathrm{kV}$ and $3.4 \mathrm{uA}$ and was run for one minute for each reading. The analysis compared the relative number of counts per second of particular elements at this voltage setting by using ARTAX software to calculate the net area under each elemental peak. This data was then processed through Microsoft Excel for final analysis (see Bedford 2013).

The results of this project verified the ability of the pXRF to differentiate chemical signatures within the pictographs; importantly, in some instances the readings of red pictographs that were visually indistinguishable contained different ratios of iron to strontium, suggesting that 
either different sources of red ochers were used to create the paintings, or that different processing methods/binding agents may be behind the different signatures.

Bedford et al. (2014) have followed this up with intensive work at the site of Three Springs, testing different statistical approaches which show the ability to analyse large spectral datasets. Figures 4 and 5 show how percentage and relative iron percentages can be processes to interrogate these data. As demonstrated below in our case study from Panel $\mathrm{C}$ at Pleito, this ability to differentiate red pigments substantially enhances our ability to interpret sequences. But, in order to do so, we need to increase the readings per panel in order to gain the quantity of data to analyse complex superimposed panels.

Figure 4. Distribution of pigment types at Three Springs according to percentage analysis. The site known as Three Springs has similar sandstone host rock and paintings as those at Pleito. The large central figure is known as Blueboy. (Image by Clare Bedford)

Figure 5. Relative iron percentages in readings from red motifs at Three Springs Panel A around and including Blueboy. Circles demonstrate groups of readings identified (Pigment groups: A- pinwheel to left of Blueboy; C- aquatic motif to left of Blueboy; G- Blueboy) (Image by Clare Bedford)

\section{2. portable Raman}

Vibrational spectroscopies, such as Raman, are excellent methods for the analysis of a wide range of materials as they are cost-effective, non-destructive and require no or simple sample preparation. When monochromatic (single wavelength such as a laser) light comes into contact with matter it can be scattered by the particles under irradiation. The inelastic scattering provides a chemical fingerprint of the sample, this is termed Raman spectroscopy. Raman technology is excellent for analysis of organic binders (sometimes called 'carrying agents'). This technique can be used in situ, providing a unique capability to collect spectra in a variety of environments. While we did not utilize pRaman in our pilot work on in situ material, below we discuss preliminary lab work to identify blood as a potential binding agent.

2.3. Pre-field work and lab based spectral analysis 
Ethnographic accounts from the South-Central California region suggest a wide variety of possible binding agents such as animal blood (deer/antelope/elk especially); human blood; animal fat; charcoal, milkweed, and a viscous lipid from wild cucumber (see Grant 1965: 86; Reeves et al. 2009). Previous studies of pigment cakes and exfoliated rock art fragments have confirmed the presence of binding agents including blood from human and animal (see Scott et al. 1996 and Edwards et al. 1998) but studies typically only identify the presence of organic components with some degree of ambiguity as to a) environmental contamination and b) source of the organic signature (Scott et al. 2002).

In addition to in situ analysis of paintings, we will develop a reference pXRF and Raman database of pigments based upon analysis of a library of pigments recovered from Pleito and other nearby sites on the preserve. Our project has obtained over 40 pigment samples (with over 700 individual pieces of pigment) sourced locally in the form of exfoliated fragments at Pleito plus pigment from archaeological deposits recovered from the excavations at the rock art sites mentioned above. This database will be continually updated from source collection and experimental preparations of different pigments and binding agents during the project. These samples will allow for an initial assessment of the viability of Raman in analysing pigments and potential binders from the region.

We tested a pigment sample from our excavations and compared the spectra to horse blood samples. Horse blood was use as it is readily available in our forensics laboratory and is widely used in numerous lab settings for testing as a proxy for human or other animal blood. Raman Spectra were acquired with 532 nm (Filter used: 10\% ) laser using a x50 LWD Objective on a Horiba LabRam HR. Spectral background readings were subtracted using a $5^{\text {th }}$ order polynomial and spectral manipulation was performed using LabSpec 6. All peaks are organic molecules.

Figure 6. Raman spectra of horse blood (A) and pigment (B) sample from excavated deposits. Both confirm presence of organic components (image by Matthew Baker).

There are clear spectral differences that are observable between the binder (blood) and the pigment and these are due to the molecular differences in the samples (Figure 6). Certainly this demonstrates Raman is sensitive in analysing potential binders on our materials.

As part of this project, controlled experiments will move forward to determine the effect that the background substrate, binders, source material and processing techniques have 
on the pXRF and Raman readings which are gathered in situ. Raw materials will be gathered from the Wind Wolves Preserve, processed by grinding, pounding and mixing with various binders, and then applied to a range of rock surfaces. We have already established this procedure in our previous experiments replicating the colour palette at Pleito using local sources (Figure 7) (see Reeves et al. 2009).

Figure 7. Experimental work with binding agents and colourants in process. The pods are from wild cucumber containing a viscous substance, an ethnographically known source of binding agent for paints in South-Central California. The Gordian Knot project will test this substance to obtain spectra for comparison with in situ readings as well as from pigment recovered in excavated deposits (Photo by Dan Reeves).

Pigments will be analysed at each stage of preparation and examined in situ once applied to the rock. This is to establish the effect of different stages of the process on the final readings, and to establish the effect of the background substrate on these readings. PXRF will be used to identify inorganic chemical elements in the pigment and background substrate to identify principle components and trace elements. Our experimental approach will gather spectra on the binding agents listed above (plus others found in ethnographic research) in order to address these issues. Handheld Raman will be used to supplement the pXRF analysis by identifying organic materials such as binders and will be used at 532nm and 1064nm in order to establish the best setting for examining in situ rock art. This technique may support the distinctions between materials which are established using pXRF and are likely to be able to distinguish materials and identify components which pXRF cannot. As such they will add valuable information to the study and give greater confidence to conclusions drawn when examining in situ rock art. Importantly, the research will include a comprehensive ethnographic literature search to a) identify possible painting recipes; b) to gain an emic interpretation of indigenous views of pigments, paints, and associated practices (see Robinson 2004).

\subsection{Comparing Raman and XRF}

Our field instrument will be the iRaman Plus developed by BW Tec. The irradiated area aht the iRaman Plus focusses upon is variable from $14 \mu \mathrm{m} \mathrm{x} \sim 0.9 \mathrm{~mm}$. Our methodological development in the lab is essential to ensure consistency and repeatability in the field to 
energy output and aperture settings. The Bruker pXRF focusses upon a $2 \mathrm{~mm}$ circle. Its use as a handheld device means that we can rapidly gather data. Over the next several years, our aim is to take $\sim 300 \mathrm{pXRF}$ readings per panel ( $\sim 3600$ reading). The efficacy of doing this is outlined in our pilot study on Panel C (see below) where we have taken 275 readings. To complement this, we aim to take as many pRaman samples as possible, up to the $\sim 300$ per panel: however, as outlined above, we are in the developmental stage of using: while the iRaman Plus is also a handheld device, there are operational aspects which may require us to employ a stand to gather readings, which may limit the total readings. So, our estimated number of readings will be between 5000 to 6000 or more readings across all panels and all elements in the Main Cave at Pleito. This represents an exponential leap in terms of chemical sourcing of rock paintings. For instance, Huntley et al. (2011) performed a ground breaking study that charted chemical sequences in rock paintings from Australia that only utilized 15 samples: these of course had to be collected and analysed in a lab. As for in situ analyses, Olivares et al. (2014) study achieved $\sim 140$ reading at La Peña de Candamo Cave in Northern Spain using pRaman while Bedford's (2013) study obtained 411 samples from the Wind Wolves Preserve.

Clearly, the research here will eclipse our pre-existing work to date by creating the most detailed chemical signature 'map' of all panels, allowing for spatial and temporal comparison. As far as penetration, both devices investigate surface areas with penetration dependent upon the geochemical variation of what is being analysed: in other words, the depth of pXRF and pRaman devices is dependent upon the material constituent of the rock art itself. Huntley (2012) has discussed various issues related to XRF analysis of pigments in Australia and issues of X-ray depth. This was an issue recognized in Bedford's (2013) master's work as 'overshot' in the sense that background host rock, underlying pigments, and especially pigment thickness can potentially influence readings. The experimental work will help address issues of potential 'overshot' by experiments that will measure host rock, single painting events on host rock, over painting events, and comparisons with changes in pigment readings in each stage of the experiments, providing a dataset to interpret against the data compiled from the site itself.

\subsection{Spectral Imaging}

New methods of spectral and computational analyses of rock art are transforming the way rock art researchers record and interpret. Easily portable technologies utilizing relatively 
inexpensive equipment or modified digital SLR cameras such Highlight Reflective Transformation Imaging (H-RTI) and dStretch@ programming can capture in situ data allowing for image enhancement to a) reveal indistinct imagery; b) clarify painting superimposition; c) investigate micro-topography, amongst other applications. A plethora of recent studies and publications demonstrate the usefulness of these portable techniques both in the field and further complemented with post-processing computations (see Mudge et al. 2012).

Highlight Reflective Transformation Imaging (H-RTI) is a portable, non-contact, nondestructive computational photographic method that captures surface shape and colour, enabling interactive re-lighting from any direction. dStretch $\bigodot$ is an image enhancement technique specifically designed to enhance fugitive elements, particularly effective with paintings. Previous work has proved RTI and its most common fitting algorithm, Polynomial Texture Mapping (PTM), significantly contributes to analysis, conservation and digital representation for various outputs and purposes (Earl et al. 2010). RTI has found applications in a broad range of materials and artefact types, including painted surfaces and particularly rock art (Mudge et al. 2006; Diaz-Guardamino and Wheatley 2013). Via interactive relighting of surfaces provided by RTI visualization, minor surface topography variations can be detected, enabling enhanced examination and analysis. The advanced perception of three dimensionality introduced by RTI can assist in the examination of superimposition, materials and techniques, and painting history of surfaces. Standard imaging equipment is used for capturing RTI data (dslr camera, flash, standard and macro lenses, tripod, remote controls) and RTI targets (shiny reflective balls). For processing and viewing RTIs open source software is used (RTI viewer, PTM viewer, RTI builder). IR and UV led radiation sources and filters will be used for capturing multispectral images.

While we have not yet applied RTI to the rock art of Pleito, we have performed preliminary work with $\mathrm{dStretch} \odot$. This is a free plug for Photoshop@ and digital SLR cameras which has already transformed rock art research with a number of publications showing its applicability for discovering overlook imagery (such as at Ankor Wat, Tan et al. 2014) or in superimposition analyses (Gunn et al. 2010). DStretch $\odot$ is a digital imaging tool utilizes a decorrelation stretch of a colour photograph to enhance the appearance of rock art. The images produced by the program are entirely false-colour, but enable one to see even the faintest colours and hues in striking clarity and contrast. This method can be exceptionally useful when dealing with faint and eroded rock art that may not be apparent to the naked eye. Decorrelation stretches were developed at the Jet Propulsion Labotory (NASA) in the 1980's. 
Originally created for remote sensing through aerial and satellite imagery, decorrelation stretches have since found a wide range of uses. The process utilized by dStretch@ works by converting a given image (typically in RGB colour space) into a new colour space (LAB, CRGB, YDS, YBR, YBK, LRE, etc.). A Karhunen-Loeve transform is then used to decorrelate the color space variables of the image. The program then equalizes the colour variance (i.e. stretching), and the data is then transformed back into an approximation of the original RGB colour space. For further discussion on the theory and mathematics behind dStretch@ see Alley (1996).

The resulting dStretch $\odot$ image is false-colour, but as our aim is to distinguish between different elements, styles, and to discern their superimposition, it works quite well. As can be seen in Figure 8, the colour differences of the input image have been stretched, yielding greater clarity of each element. DStretch $\odot$ images allow greater inquiry into the structure, form, execution, and superimposition of elements..

Figure 8. Left, detail closeup of a portion of Panel $\mathrm{H}$ in the Gordian Knot illustrating the complexity of the superimposition; right, $d$ Stretch $\mathbb{C}$ image showing the potential for 'false colour' out-puts to clarify imagery (images by Devlin Gandy),

For this reason, it is of great value for studying the panels at Pleito. The 12 panels of Pleito's Main Cave are all in varying states of decay. Indeed, a great portion of the Main Cave's prehistoric extent has been lost. Though certain panels like A, C, E, and H offer glimpses of its execution and dramatic scale, they are each bounded by rock spall and erosion. Furthermore, as mentioned previously, many of these panels have a great degree of superimposition of elements which have collectively constituted layers. These layers may fall within certain stylistic tradition that may appear distinctive not only of a particular artisan but a particular time. Certain elements may as well appear to be the product not of one hand, but of numerous artisans, conceivably over distant time spans. Unfortunately, much of this is scarcely visible to the unaided eye as erosion and superimposition have cumulatively rendered some of the panels visually daunting and confusing, leaving many aspects latent. Through dStretch $\odot$ analysis this daunting and confusing array of imagery is made tangible and clear as shown by our initial test of the Gordian Knot as can been seen in Figure 8.

Figure 9. Left, detail of Panel $\mathrm{H}$ in the Gordian Knot; right, anthropomorphs and geometrics clarified with dStretch $\odot$ (images by Devlin Gandy). 
In Figure 9, latent anthromorphic elements become clearly visible through the use of $\mathrm{dStretch} \odot$. Superimposition also becomes remarkably clearer, and what might have appeared as 3-4 layers to the naked eye becomes 6, 7, or more possible layers of superimposition.

In Figure 10, a faint painting within a spalled section of rock is very difficult to discern. Though the painting's location on a spall surface within a larger panel suggests it is of a younger age than the surrounding paintings, the rock surface it is painted upon is of a lower quality than the surrounding cave wall. For this reason, this section has undergone dramatic aging, making distinguishing the style and elements difficult. But, with dStretch $\circledast$ these elements can be clearly discerned, recorded, and compared to other sites.

Figure 10. Left detail of Panel H, in the Gordian Knot; right, "Insect" and "Plant" motifs painted within an area where the previous rock surface has spalled away (images by Devlin Gandy).

These layers of superimposition hint at great antiquity of the panel as well as continued usage and modification of the site, likely into the historic period (Reeves et al. 2006, Robinson 2006). So, while we have only begun work on the Gordian Knot sketched above, we further show how dStretch $\odot$ can complement the pXRF data in our Panel C study below.

\subsection{Digital Layers Technique to Establish a Harris Matrix}

To create a relative chronology enabling chemical and molecular sequencing, plus to interpret changes in iconography through time, we will unravel the superimposed painting events. The Rock Art Documentation Group (a Southern Californian rock art documentation specialist group comprising Rick Bury, Antoinette Padget, and Dan Reeves) piloted a 'Layer's

Separation' technique utilizing high resolution digitized photographs and various functions of Photoshop@: they successfully separated multiple major painting events in two of the panels at Pleito (panels C/E) (see Figure 11, plus discussion of Panel C below) (Bury et al. 2003).

Figure 11. Layer drawings of superimposition sequence from Panel E at Pleito, Main Cave; top left - first discernible but ephemeral traces in red and black; top right - second layer is characterized by a grid and a pinwheel element, with red, black, white, and a trace of creamy- 
white; bottom left - a composition set-piece is superimposed over the earlier elements. Aqua blue is introduced, outlined in white and red. A red-white-red circle encompasses a classic set-piece: a central figure is flanked by radial elements with an aquatic figure in aquablue and red; bottom right - a final composition caps the earlier elements: lavishly applied orange, white, red, and black interplay with the earlier circular composition. Two plummet shaped elements, perhaps representing charmstones, are superimposed over the earlier setpiece. One plummet has a white-dotted foot as an appendage (drawings by Dan Reeves).

This technique enables the elements from an isolated 'stratum' to be copied onto an independent digital layer, stacking each stratum in order allows for the overall sequence to be constructed (see Brady and Gunn 2012: 633, for description of a similar approach). We will complete Layer's Separation of the remaining panels at including the superimposed panels $\mathrm{B} / \mathrm{D}$, plus the conjoined panels of $\mathrm{J} / \mathrm{K}$ and the Gordian Knot $(\mathrm{A} / \mathrm{G} / \mathrm{H})$. H-RTI and dStretch $\odot$ analyses (see above) will aid identifying sequences as well as fugitive (i.e. partial/nondiscernible to the naked eye) elements. Once completed, this will give us multiple separated superimposed panels to allow for stratum comparison across the cave: this will allow for a comprehensive Harris Matrix to be constructed and allow comparisons between stylistic form and chemical components through time (see Loubster 1997. Russell et al. 2000; Swart 2004 for other examples of the Harris Matrix applied to rock art)

This approach will open new vistas into interpreting rock art from a multidimensional approach to the materiality of pigment and painting. Establishing a Harris matrix will enable a data-rich informed interpretation of the materiality of pigment. Data for each element will include colour, chemical composition, potential binding agent, method of application, and style. Using these multiple variables will enable us to track traditions of pigment making and application throughout sequences and across the site. A series of questions can be tested concerning relations between these variables that will give nuanced insights never before obtainable. For instance, we can compare relative use of common materials (iron oxides, manganese, etc) to exotic source material (such as antimony) and methods of production (such as optical blues) which may indicate unusual significances to particular paintings from potentially difficult to obtain sources or highly skilled methods of painting.

Importantly, we can interrogate this data to consider if some practices were institutionalised (i.e. standardized), passed down through learning networks, or highly individuated and idiosyncratic. These questions can be approached in different ways: for 
instance, standardisation can be approached by asking if formulaic set-pieces (a compositional pictograph utilizing a common arrangement of specific motifs) were constrained to particular sequences and made of common material and methods of application (Figure 12).

Figure 12. Examples of a form of 'set piece' found in South-Central California. It is defined by paired pinwheeling or concentric elements bisected by a figure; A-Alder Creek (drawn by Dan Reeves); B-Three Springs; C-Alder Creek (photographs by David Robinson; drawings by Dan Reeves). Set pieces are evident at Pleito. For instance, see Figure 10, lower left, where a similar set piece can be identified in the second to last layer of Panel E.

A high degree of standardisation would support notions that these images were made by specialists, while wide variation would argue for personal choice by the makers. This can be compared against other classes of imagery, allowing for nuances of social organization of artistic production to be revealed. With ethnographic data, we can further consider indigenous perceptions of the substances identified to put forward emic interpretations of pigment and painting. In total, this is both a quantitative and qualitative jump in terms of integrating portable technologies for powerful characterisations of sequencing and spectra, but also in terms of integrating those results to pose fresh questions which typically cannot be thoroughly broached with more limiting methods. In this sense, we argue that this research is not simply proximate to the rock art of the American West: it will contribute more than the establishment of a methodology; it will also provide a template for recasting questions that can be asked of complex painted surfaces and their sequences. We will show how combining layers separation with $\mathrm{pXRF}$ and dStretch $@$ greatly enhances our ability to disentangle sequences in our study of Panel C.

\section{3D modelling: analyses, data fusion, and heritage management}

In order to integrate all the data, from $\mathrm{pXRF}$, pRaman points to spectral imaging to layer separation, we will use a three-dimensional (i.e. 3D) model of the Main Cave overlain with a grid reference system. This model will be the 'vehicle' for both analytical and heritage purposes. We have started this procedure by scanning the main cave in 2014: while further work will fill in the surrounding rock outcrop and add more detail within the cave itself, we 
present the results so far in order to demonstrate the utility of such visualization. To do this, the (3D) data capture of Pleito utilised the Faro Focus 3D, a small lightweight scanner that was ideal for working within cramped spaces. Three scans, each including 80-90 photographs were taken inside the shelter at different positions spaced at roughly one metre intervals to cover the entire interior. Three stationary reference spheres were placed on the floor inside the shelter in order to reference the scans together. Using reference spheres within each scan these were stitched together using Scene software to produce a point cloud. This was then exported as a PTS point cloud into Cloud Compare, subsampled to reduce the file size and exported as a PLY file. Pointools was then used to render and animate the 3D model.

Video S1. Animation of the laser scan model of the Main Cave at the painted site of Pleito, California. The view circles above the cave before entering through the southern edge below Panel E. The perspective then explores the cave ceiling and multiple panels, before focusing on the Gordian Knot at the north end of the cave. The view then sweeps along the cave mouth, back to Panel E, before finishing by withdrawing to the cave exterior. (Video rendered by James Miles).

This model can be refined and added to, especially to show the exterior rock surface (see Figure 1) and the surrounding landscape. However, the laser scan also provides a cohesive 'total' view of the cave interior, allowing for the overlaying of a reference grid. In order to easily visualise the pictographs, the floor was removed or clipped from the original point cloud so that a full reference grid could be attached to an arbitrary point on the shelter's ceiling.

Figure 13. Grid overlay of 3D model of Pleito. Grid can be scaled to any dimension, allowing for highly precise location of $\mathrm{pXRF} / \mathrm{pRaman}$ readings and georeferencing of spectral imaging (image by Michelle Wienhold).

The reference grid covers all of the walls and ceiling, allowing for a comprehensive base line throughout the cave. This will be used to locate each reading taken by pXRF and pRaman, and allow the georeferencing of imaging data and layer separation. Thus, the 3D model will be fundamental to organising the integration of these portable technologies.

Importantly, the data derived from the 3-D scan data, layer separation graphics from Photoshop $\odot$, and from the $\mathrm{pXRF}$ and pRaman will form the basis for a developing a virtual 
reality model complete with specific dropdown menu options (and clickable Harris Matrix) for panels, sequences, and individual elements. This will be housed on the internet, allowing for 'virtual' access to the site for anyone with access to the web. Individual panels and the layers comprising them will be able to be freely explored, with chemical descriptions in lay and technical terms. Importantly, this virtual experience will promote an enriching experience of the rock art site without the potential harm to the paintings that physical access risks. The web site will house the Gordian Knot Spectral Database - a comprehensive list of the results of the spectral work which will be usable for researcher across the globe. A methodology section will accompany the database. With its permanent housing, future data will be able to be added, thus making it an expandable data base and add lasting project legacy and continuing impact. Along with education, the ethos of the website will promote conservation and long term care of Pleito in order to promote long term changes in the attitudes of the general populace in terms of site preservation. This ethos reflects the Wind Wolves Preserve core mission statement of preservation and conservation of the environment. The website will act as a management tool for the Preserve by acting as an alternative to site visitation. The Preserve is continually under pressure to allow visitor access to the site: this puts a potential strain upon their resources and daily operations. Also, weather may make accessing the site difficult or impossible. The website thus can be drawn upon by the Preserve to mitigate visitation while continually promoting education, thus providing a 'pressure valve' while promoting the long term aim of preserving the remarkable paintings at Pleito. While we are at the early stages of the scanning process at Pleito, we do use some of that data to demonstrate its usefulness in identifying the interplay of rock form and the form of the rock art, as well as delimiting potential areas of pigment loss.

\section{Panel C case study}

Panel $\mathrm{C}$ is a polychrome series of paintings centrally place on the ceiling of the Main Cave towards the mouth.

Figure 14. Panel C at Pleito with main rock art elements labelled A-F (original photograph by Rick Bury). 
As seen in Figure 14, this panel is comprised by a cluster of transmorphic images (elements $\mathrm{A}, \mathrm{B}, \mathrm{C}, \mathrm{D} / \mathrm{E})$, but other geometric elements can also be seen such as element $\mathrm{F}$. The positioning of the elements may suggest that the images were produced as part of a single composition. However, an initial layers separation of the panel clearly shows a minimum of three stages (Figure 15).

Figure 15. Panel C at Pleito with four clearly defined phases. Earliest phases are in the upper left, followed in sequence by upper right, lower left, and lower right (drawings by Dan Reeves).

The first stage is defined by a black and red geometric shapes; the second shows two elongated transmorphic elements with green, red, orange, black, and white; the third phase shows two more elongated figures also with green, red, orange, black, and white.

This panel was then examined using a Bruker Tracer III hand held XRF. A total of 275 readings were taken from this panel. Here we analysed the readings from the green and red pigment using principal component analysis in order to establish variation in chemical composition across the panel, and to identify contrasting pigment materials used to produce the same colour. The initial processing and deconvolutions used ARTAX software with results exported into Excel where they were converted into percentages of the total number of counts. The principal component analysis was performed using PAST software, using a variance-covariance matrix and included $\mathrm{Si}, \mathrm{K}, \mathrm{Ti}, \mathrm{V}, \mathrm{Cr}, \mathrm{Mn}, \mathrm{Fe}, \mathrm{Ni}, \mathrm{Rb}, \mathrm{Sr}, \mathrm{Y}, \mathrm{Zr}$ and $\mathrm{Nb}$. Both the red and green pigments were iron rich but there is an absence of copper in the green, indicating that the red is ochre and that the green is most likely a green earth compound rather than a copper based mineral such as hydrous copper (see Reeves et al. 2009). This is identical to other work undertaken by Scott et al. (2002), who concluded that the green pigment they analysed from exfoliated fragments collected from the floor of Pleito were green earth.

Figure 16. PCA scatterplot of green pigments from elements A and B. Readings from element A are represented by black dots and from element B by red dots. Purple dots represent readings from the thin green line to the top right of figure 1.

Analysis of the green pigments in elements A and B showed no significant groupings of contrasting readings between them (Figure 16). This indicates that the source for these 
greens is likely the same for each. However, more variation was present in the red pigments (Figure 17). Readings from red in the elements A, B, and D all showed the same chemical composition as each other. Reading from elements $\mathrm{C}$ and $\mathrm{E}$ in turn showed similarities to each other. Finally, the reds in element F contrasts with all the other areas of red in the panel.

Figure 17. PCA scatterplot of red pigments from all elements of panel $\mathrm{C}$ at Pleito. The groups of elements are labelled within the plot and the coloured dots correspond with those in figure 4 below. Element $\mathrm{A}=$ yellow, $\mathrm{B}=$ blue, $\mathrm{C}=$ pink, $\mathrm{D}=$ green, $\mathrm{E}=$ black, $\mathrm{F}=$ cyan.

Figure 18. All elements in panel $\mathrm{C}$ at Pleito with elements labelled and positions of pXRF readings marked by coloured dots.

Therefore the $\mathrm{pXRF}$ results indicate a minimum of three different red pigments in Panel C. The distribution of these pigments according to the $\mathrm{pXRF}$ results can be used in conjunction with layer separation techniques to tease out more detail in the order of rock art production in this panel. Here, it is important to pay close attention to the location of the readings in the panel and within elements (Figure 18).

Layers separation and XRF results combined indicate that it is most likely that element $\mathrm{F}$ was produced first. In fact, element $F$ shows much more widely dispersed readings than the rest of the reading, which are more neatly clustered. This may demonstrate a difference in the quality of ochre used in the initial phases of painting: the pigment recipe appears to be far less homogenous than later pigments. The next phase is represented by element $\mathrm{C}$, a red outlined black transmorph. However, the pXRF data shows that the red outlining demarcated as $\mathrm{E}$ on our scheme is identical to the red in element $\mathrm{C}$. Closer inspection of element $\mathrm{D} / \mathrm{E}$ shows that it too is red outlined black transmorph, with a zigzag red/orange infill that overlays the earlier black. The pXRF readings of this red/orange overlay is distinctly different than the red outline $(\mathrm{E})$. This suggests first that the $\mathrm{D} / \mathrm{E}$ transmoph is multisequential in composition; and that even though $\mathrm{C}$ clearly precedes $\mathrm{E}$ stratigraphically, $\mathrm{C}$ and $\mathrm{E}$ are probably part of the same phase as they share the same colour scheme (black with red outline) and chemical signature. Finally, the similarity of the pXRF readings in both the greens and the reds in A, B, and the overlay of D, all suggest that they were composed at a similar time, but again A is certainly overpainted by B showing that A was first. A revised sequence can now be posited showing a different phasing in the middle layers, suggesting at least two additional sequences (see Figure 19). In a quantitive sense, integrating pXRF with layers separation refines our series of sequences (from three to five), while in a qualitative 
sense relationships suggested between layers (i.e. green in subsequent layers) and even within the elements themselves (reds within element D/E).

Figure 19. Layer's separation of Panel C after incorporation of pXRF data (drawing by Dan Reeves and David Robinson).

We also conducted a dStretch $\odot$ analysis of the Panel C. After processing the image using the techniques described above, we then converted the image into greyscale (Figure 20).

Figure 20. Panel $\mathrm{C}$ clarified with $\mathrm{dStretch} \odot$ and then reprocessed into a grey scale image (Image by Devlin Gandy).

The result allow us to clearly see elements in additional layers. For instance, a red line is seen running behind all of the transmorphic figures, and underneath the black. This clearly predates the transmorphic figure and may relate to element $\mathrm{F}$ in the earliest layer. Also, a sun/mandala figure can be seen in the lower portion of the panel. This also appears to be under element $\mathrm{A}$. We will revisit this panel for more $\mathrm{pXRF}$ work to see if we may be able to relate these elements chemically to the rest of the sequence.

Finally, we consider the topography of the surface by using a 'tear out' of Panel C documented in our 3D model (Figure 21).

Figure 21. A tear-out laser scan image of Panel C, looking from the rear of the cave towards the mouth (image by James Miles).

The image allow us first to identify areas of pigment loss due to natural processes as it clearly shows the scalloping effect of the exfoliation of the sandstone surface and substrate, confirming blank areas in our imaging data in that portion of the panel having such extreme exfoliation. More importantly, the model can be employed to consider how the artist may have chosen to ignore or react to the shape of the rock. Here, the topography of this portion of the cave ceiling forms a lobe that drops lower than the rest of the cave aperture. This creates a kind of elongated peninsular effect in the shape of the ceiling at this central portion of the cave. It is interesting that while the earlier layers with the geometric shapes do not seem to have been placed in reference to this shape, the transmorphic images follow this peninsula in their elongated forms while pointing towards the aperture with all of their heads towards the 
drip line. This shows that, potentially, there was a change in how the cave surface was interpreted by the artists through time.

In short, the laser scanning of the cave allows us to investigate the micro-topography of the cave and how the artists may or may not have referenced the shape of the rock surface in their painting. While we are yet to conducted Raman or RTI analyses, this example shown here of layers separation, $\mathrm{pXRF}, \mathrm{dStretch} \odot$, and laser scanning illustrates how integrating these methods affords us the opportunity to achieve a much greater analysis of the rock art than using these techniques on their own.

\section{Conclusion}

This paper has outlined how integrating portable technologies can potentially transform our research into complex painting rock art sites. Individually, each approach - from chemical spectra analytics such as pXRF and pRaman, to laser scanning and imaging multispectral techniques such as H-RTI and dStretch $\odot$ - has shown great applicability. However, the integration of these approaches offers the ability and opportunity to garner far more complete analyses of complex sites than they can provide individually. Our research aims to fully integrate portable imaging and spectral technologies to develop a robust and detailed methodology to look at change through time in the sequence of painting events at Pleito. Doing so also enables the management of fragile resources while opening up new means of informing a variety of audiences, both across the academy, for stakeholders, and the wider public in general.

In summary, the methodology discussed above can be sketched out as:

1) On site H-RTI/dStretch@ capture/processing of colour and surface topography.

2) Laser scan main cave, establish grid reference point system.

3) Conduct on site fieldwork to record the pictographs using pXRF and pRaman.

4) Create a Harris matrix of the site to unravel the series of superimposition events.

5) Experimental pigment processing to create spectral database for comparison. Lab based Raman work to contribute to spectral database/refine field methodology.

6) Integrate results in spectral database.

7) Conduct ethnographic research on perceptions of pigments and sources.

8) Conduct multivariate analyses to address series of research questions. 
9) Integrate data into experiential web environment.

Critically, the application of new technologies within digital 3-D environments offers the opportunity to fuse research and heritage needs, especially at fragile sites such as Pleito. At this stage, the Gordian Knot Project is in its early stages. Focussing on Panel C, we have presented some of our initial results demonstrating the utility of integrative approaches. At this point, it is too early to draw inferences about social change from this one panel. But clearly we can see change through time in Panel C: chemical and iconographic change, as well as change in the use of the rock surface. The change from geometric to transmorphic images is certainly similar to that seen in Panel D (see Figure 11). This may be indicative of a broader artistic change from geometric to transmorphic imagery and set pieces that ultimately correlates with changes within the local populace and the emergence of a complex Chumash society. However, chemical readings indicate greater complexity to the sequence, and dStretch $\odot$ imaging shows further layers and elements to be considered. It is too early to have any certainty concerning the overall sequence and it wider implications at Pleito. Utilising a broad array of methods, this research will continue to unravel the chemical, chronological and potential social aspects of the complex rock art at Pleito and establish methodologies that will have applications for rock art sites around the globe.

Acknowledgements: We thank Rick Bury, Vicki Cummings, Antoinette Padget, Carole Bury, Bonnie Whitney, D. C. Clendenen, Sheryl Clendenen, John Harmon, John Johnson, Unika Delpino-Mark, Rick Peterson, and Fraser Sturt. We also thank the Institute for Field Research and the students who assisted in gathering data on Panel C. Special thanks to Robert Crewe for his field assistance while scanning Pleito. Thanks also to Guillaume Robin for the invitation to publish in this special issue. Further thanks to the three anonymous referees who reviewed the first draft of this paper. Finally, we thank Dan York of the Wildlands Conservancy and the staff of the Wind Wolves Preserve for their permission and support for this research. This project has been awarded funding by the Arts and Humanities Research Council (AHRC) 'Unravelling the Gordian Knot: Integrating Advanced Portable Technologies into the Analysis of Rock-Art Superimposition' (Grant number AH/L014041/1). 


\section{References}

Alley, R.E. 1996. Algorithm theoretical basis document for Decorrelation stretch. Report prepared for NASA, Jet Propulsion Laboratory. Oak Grove, Pasadena, California.

Bedford, C. 2013. Characterising Chumash Rock Art Pigments Using Portable XRF

Technology. MSc (Res) Thesis. School of Forensic and Investigative Sciences, University of Central Lancashire

Bedford, C., D.W. Robinson, F, Sturt, and J. Bernard. 2014. Making paintings in South Central California. A qualitative methodology for differentiating between in situ red rock art pigments using portable XRF. Proceedings of the Society for California Archaeology 28:286296

Barham, L.S. 2002. Stytematic Pigment Use in the Middle Pleistocene of South-Central Africa. Current Anthropology 43(1):181-190.

Brady, L.M., and R.G. Gunn. 2012. Digital enhancement of deteriorated and superimposed pigment art: methods and case studies, pp. 627-643. In J. McDonald and P. Veth (editors) A Companion to Rock Art. Blackwell: Oxford.

Bury, R., A. Padgett, and D. Reeves. 2003. The Pleito Project. Documentation of CA-KER77 Rock Art. Report submitted to the Wind Wolves Preserve and The Wildlands Conservancy.

Chippindale, C. and G. Nash. 2004. Pictures in place: approaches to the figured landscape of rock-art. In C. Chippindale and . Nash (editors) The Figured Landscapes of Rock-Art: Looking at Pictures in Place. Cambridge University Press: Cambridge.

Diaz-Guardamino, M. and D. Wheatley. 2013. Rock art and digital technologies: the application of Reflectance Transformation Imaging (RTI) and 3D laser scanning to the study of Late Bronze Age Iberian stelae. MENGA. Journal of Andalusian Prehistory, 4, 187-203

Earl, G., K. Martinez, and T. Malzbender. 2010. Archaeological applications of polynomial texture mapping: analysis, conservation and representation. Journal of Archaeological Science 37(8):2040-2050. 
Edwards, H.G.M., L. Drummond, and J. Russ. 1998. Fourier-transform Raman spectroscopic study of pigments in native American Indian rock art: Seminole Canyon. Spectrochimica Acta Part A 54:1849-1856.

Grant, C. 1965. The Rock Paintings of the Chumash. University of California: Berkeley.

Grant, C. 1978. Interior Chumash. In California, edited by Robert F. Heizer, pp. 530-534. Handbook of North American Indians, Vol. 8, William Sturtevant, general editor. Smithsonian Institution, Washington, D.C.

Grasse, Gale. 2005. The Pleito Puzzle: An interim report on the excavations at CA-KER-77, Bakersfield, CA. Paper presented at the Society for California Archaeology General Meetings, Sacramento, California.

Gunn, R.G., C.L. Ogleby, D. Lee, and R.L. Whear. 2010. A method to visually rationalise superimposed pigment motifs. Rock Art Research 27(2):131-136.

Huntley, J. (2012) Taphonomy or paint recipe: In situ portable X-ray fluorescence analysis of two anthropomorphic motifs from the Woronora Plateau, New South Wales. Australian Archaeology 75

Huntley, J. Watchman, A. and J. Dibden, 2011. Characteristics of a pigment art sequence: Woronora plateau, New South Wales. Rock Art Research 28(1):85-97

Lee, G. 1979. The San Emigdio rock art site. Journal of California and Great Basin Anthropology 1(2):295-305.

Loubster, J.H.N. 1997. The use of the Harris Diagram in recording, conserving, and interpreting rock paintings. International Newsletter on Rock Art 18:14-21.

Mudge, M., Malzbender, T., Schroer, C., and M Lum. 2006. New Reflection Transformation Imaging Methods for Rock Art and Multiple Viewpoint Display. Proceedings of the 7th International Symposium on Virtual Reality, Archaeology and Cultural Heritage (VAST2006). (Ioannides, M., Arnold, D., Niccoluchi, F. and Mania, K., eds.), Eurographics Association, pp. 195-200.

Mudge, M., C. Schroer, T. Noble, N. Matthews, S. Rusinkiewicz, and C. Toler-Franklin. Robust and scientifically reliable rock art documentation from digital photographs, pp. 644659. In J. McDonald and P. Veth (editors) A Companion to Rock Art. Blackwell: Oxford. 
Olivares, M. Castro, K. Corchón, M.S. Gárate, D. Murelaga, X. Sarmiento, and A.

Etxebarria. 2013. Non-invasive portable instrumentation to study Palaeolithic rock paintings: the case of La Peña Cave in San Roman de Candamo (Asturias, Spain) Journal of Archaeological Science 40(2):1354-1360

Pike, A.W.G., D.L. Hoffman, M. Garcia-Diez, P.B. Pettitt, J. Alcolea, R. De Balbin, C. González-Sainz. C. de las Heras, J. A. Lasheras, R Montes, J. Zilhão. 2012. U-Series Dating of Paleolithic Art in 11 Caves in Spain. Science 336(6087): 1408-1413.

Pitarch, A., J.F. Ruiz, S Fdex-Ortiz de Vallejuelo, A. hernanz, M. Maguregui, and J.M. Madariaga. 2013. In situ characterization by Raman and X-ray fluorescence spectroscopy of post-Paleolithic blackish pictorgraphs exposed to the open air in Los Chaparros Shelter (Albalate del Arzobispo, Teruel, Spain). Analytical Methods 6:6641-6650.

Reeves, D., R. Bury and D.W. Robinson. 2009. Invoking Occam's Razor: Experimental Pigment Processing and an hypothesis concerning Emigdiano Chumash rock-art. Journal of California and Great Basin Anthropology 29(1):59-67.

Robinson, D.W. 2006. Landscape, taskscape, and indigenous perception: the rock-art of South-Central California. Unpublished Ph.D., Department of Archaeology, University of Cambridge.

Robinson, D.W. 2007. Taking the Bight Out of Complexity: Elaborating South-Central California Interior Landscapes, pp 183-204. In Sheila Kohrning and Stephanie Wynne-Jones (editors) Socialising Complexity: Structure, Integration, and Power. Oxbow: Oxford.

Robinson, D.W. 2010a. Land use, land ideology: an integrated Geographic Information Systems analysis of the Emigdiano Chumash rock-art, South-Central California. American Antiquity 74(4):792-818.

Robinson, D.W. 2010b. Resolving archaeological and ethnographic tensions: a case study from South-Central California, pp 84-109. In D. Garrow and T. Yarrow (editors), Archaeological Anthropology: understanding similarities, exploring differences. Oxford: Oxbow.

Robinson, D.W. 2012. Legitimating Space: Art and the Politics of Place. Special Issue, Art Makes Society, John Robb and Elizabeth Demarais (eds), World Art (3): 129-134. 
Robinson, D.W. 2013a. Transmorphic Being, Corresponding Affect: Ontology and Rock-Art in South-Central California. In Benjamin Alberti, Andrew Jones, and Joshua Pollard (eds.) Archaeology After Interpretation: returning materials to archaeological theory, pp. 59-78. Left Coast Press; Walnut Creek, California.

Robinson, D.W. 2013b. Drawing Upon the Past: Temporal Ontology and Mythological Ideology in South-Central Californian Rock-Art. Cambridge Archaeological Journal 23(3):373-394.

Robinson, DW and F. Sturt. 2008. Towards Articulating rock-art with archaeology: an interim report of the Pinwheel Cave rock-art and bedrock mortar complex (CA-KER-5836 \& 5837), Kern Country, California. Kern County Archaeological Society Journal 10:25-44.

Robinson, DW, F. Sturt and J. Bernard. 2010. Enculturating Environments: rock-art and the interior of South-Central California. Antiquity 84:232, Project Gallery, accessible at: http://antiquity.ac.uk/projgall/robinson323/

Russell, T. 2000. The application of the Harris Matrix to San Rock Art at Main Cave North, Kwazulu-Natal. The South African Archaeological Bulletin 55(171):60-70.

Scott, D. A. Newman, M. Schilling, M. Derrick, and H. P. Khanjian, 1996. Blood as a binding medium in a Chumash Indian pigment cake Archaeometry 38(1): 103-112.

Scott, D.A., S. Scheerer, and D.J. Reeves. 2002. Technical examination of some rock art pigments and encrustations from the Chumash Indian site of San Emigdio, California. Studies in Conservation 47(3):184-194.

Swart, J. 2004. Rock art sequences in uKhahlamba-Drakensberg Park, South Africa. Southern African Humanities 16:13-35.

Tan, N.H., I. Sokrithy, H. Than, and K. Chan. 2014. The hidden paintings of Angkor Wat. Antiquity 88(340):549-565.

Tournie, A., L.C. Prinsloo, C. Paris, P. Colomban, and B. Smith. 2010. The first in situ Raman spectroscopic study of San rock art in South Africa: procedures and preliminary results. Journal of Raman Spectroscopy 2011(42): 399-406. 
Wienhold, M. 2014. Spatial analysis and Actor-Network Theory: a multi-scalar analytical study of the Chumash Rock Art of South-Central California. Unpublished Ph.D., School of Forensic and Investigative Sciences, University of Central Lancashire. 
Click here to download high resolution image

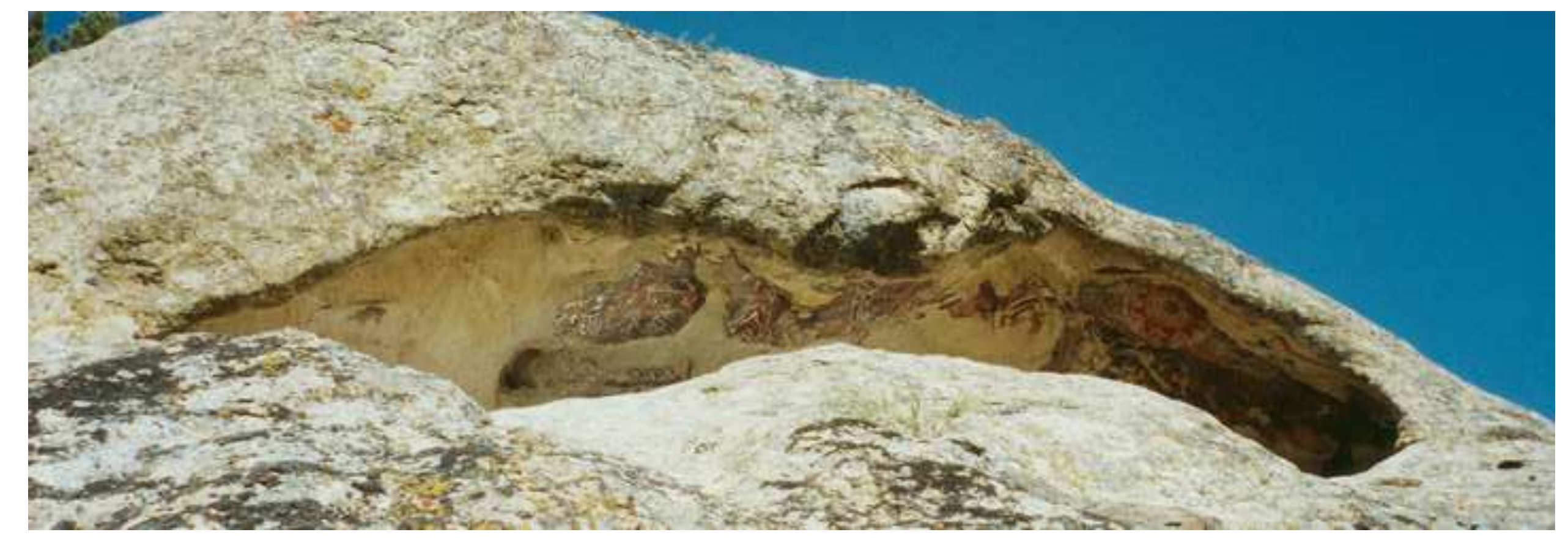


Click here to download high resolution image

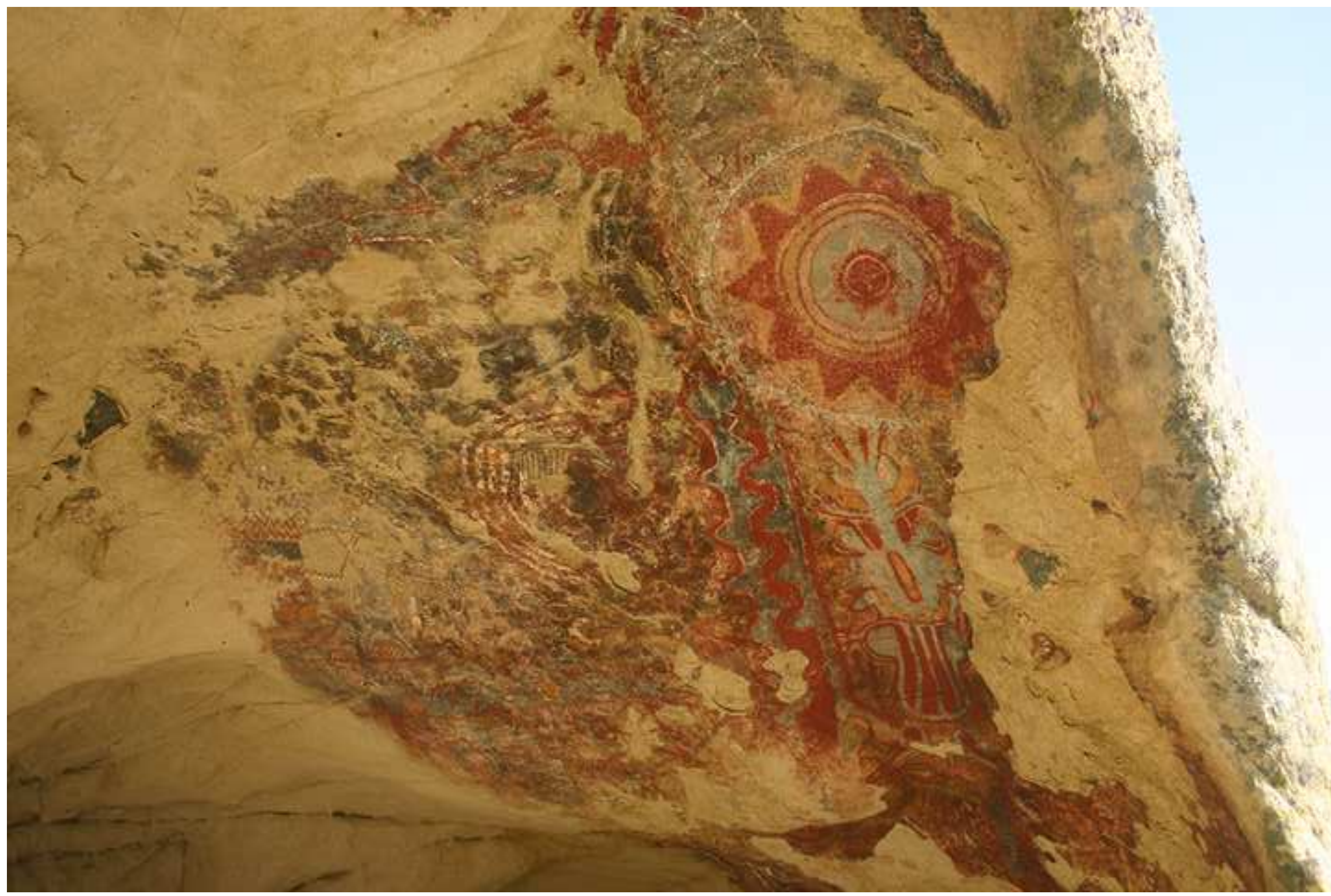




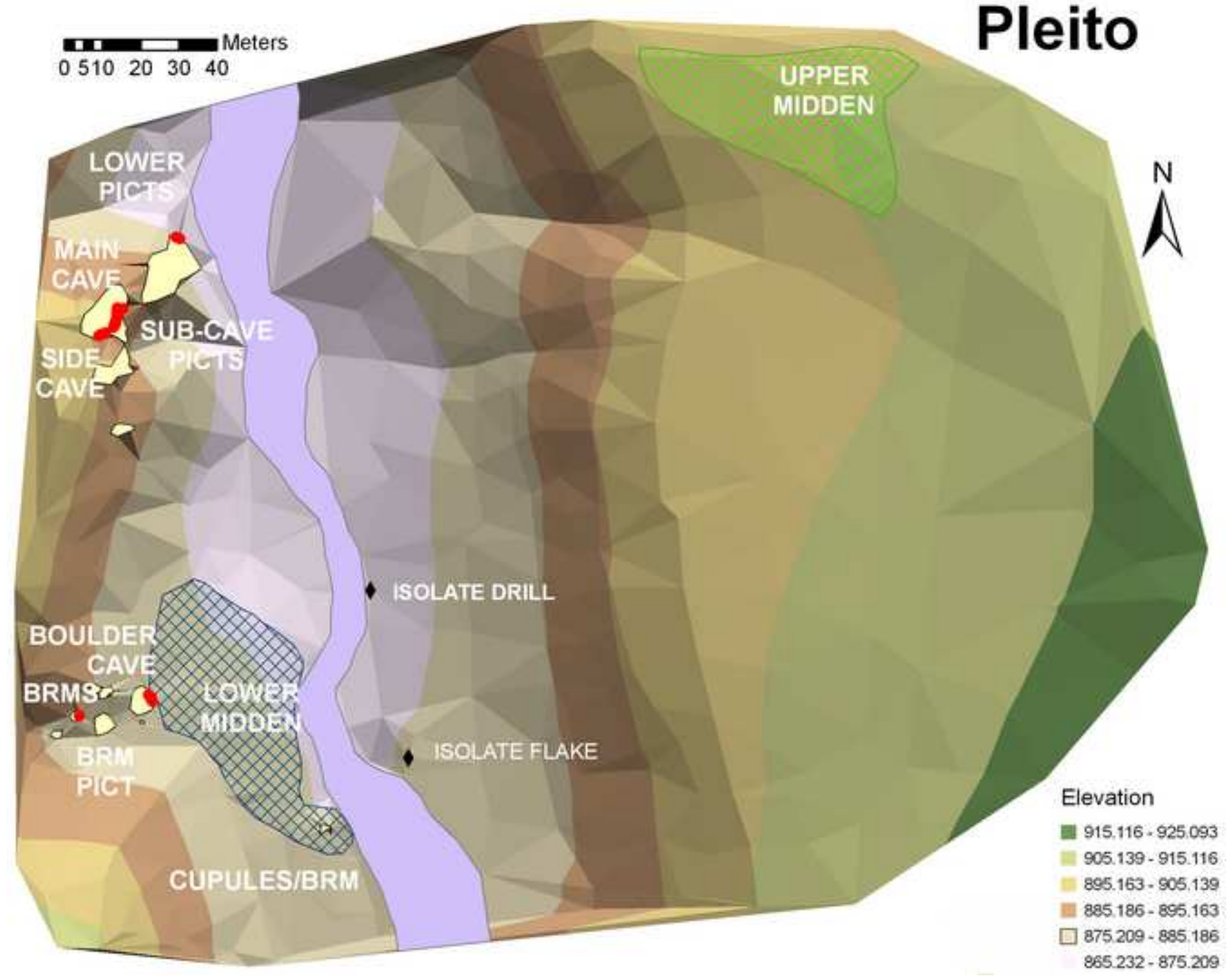




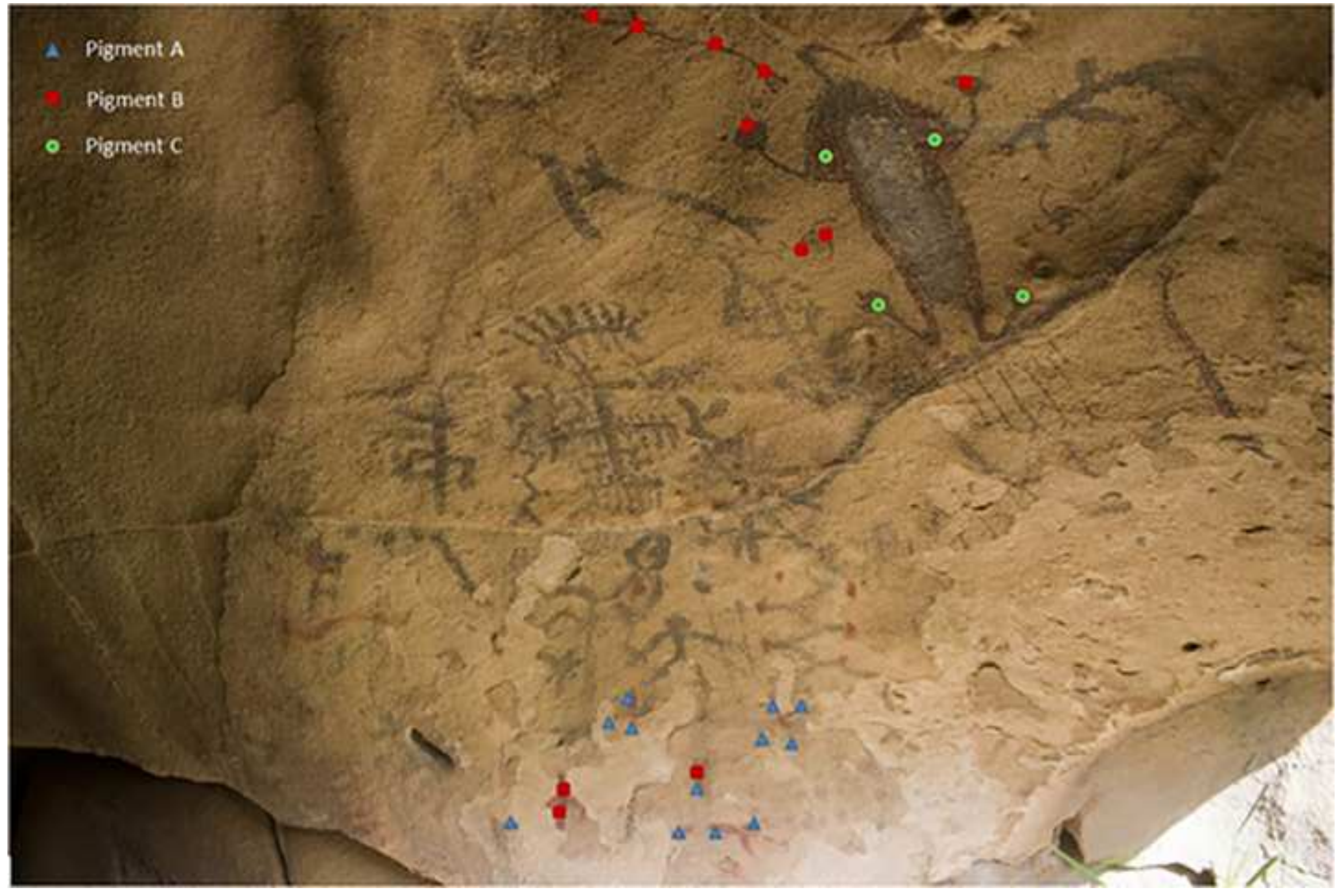

A. Pigment A

Pigment 8

- Pigment C 
Three Springs Zoomorph Fe \%

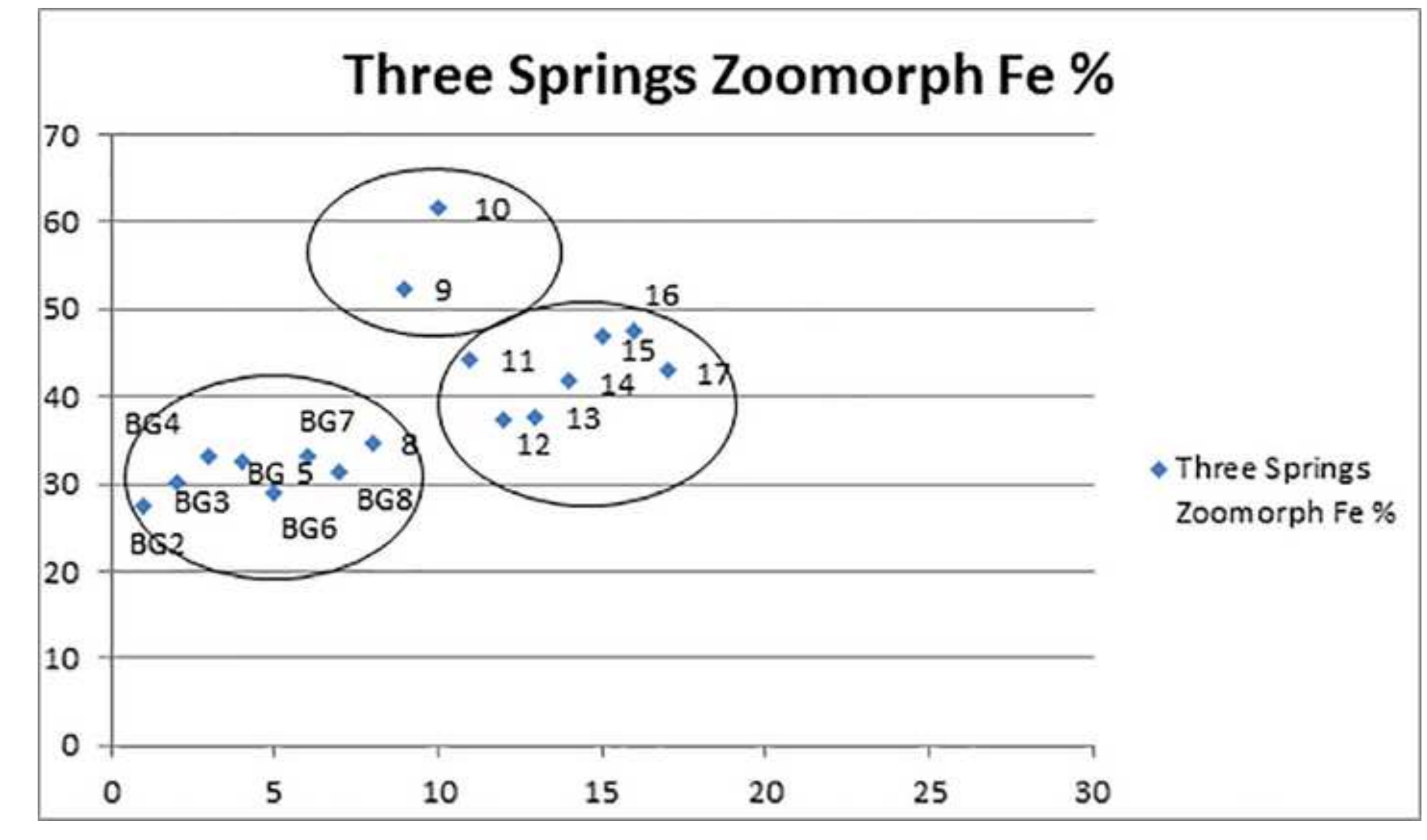



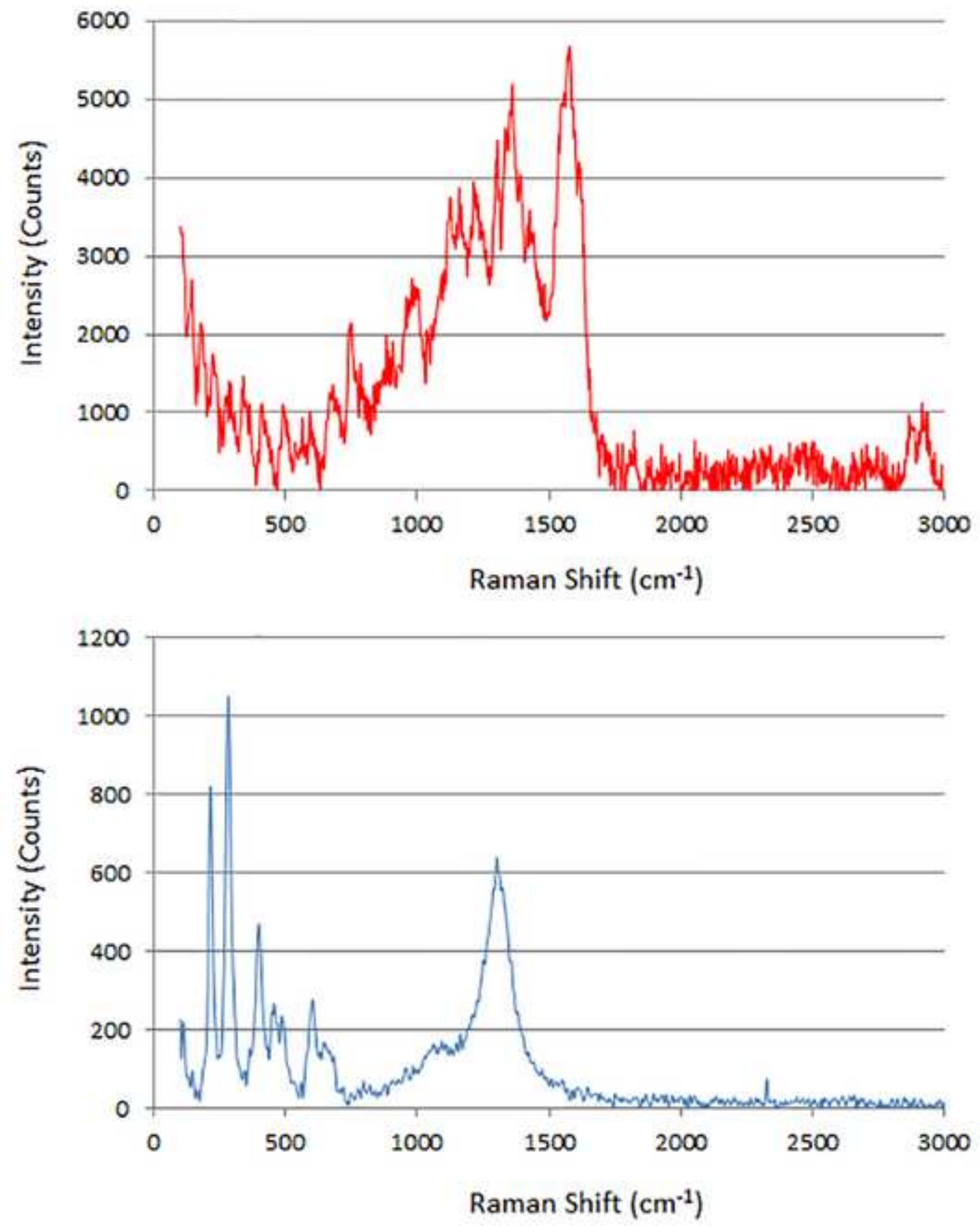
Click here to download high resolution image

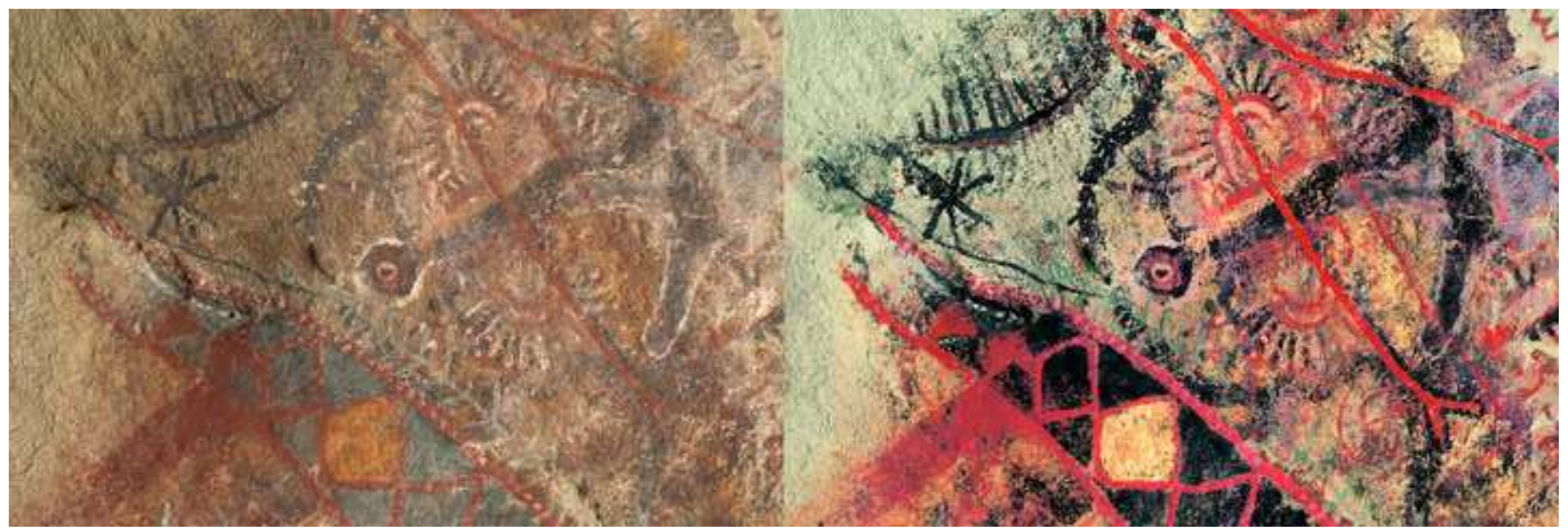


Click here to download high resolution image

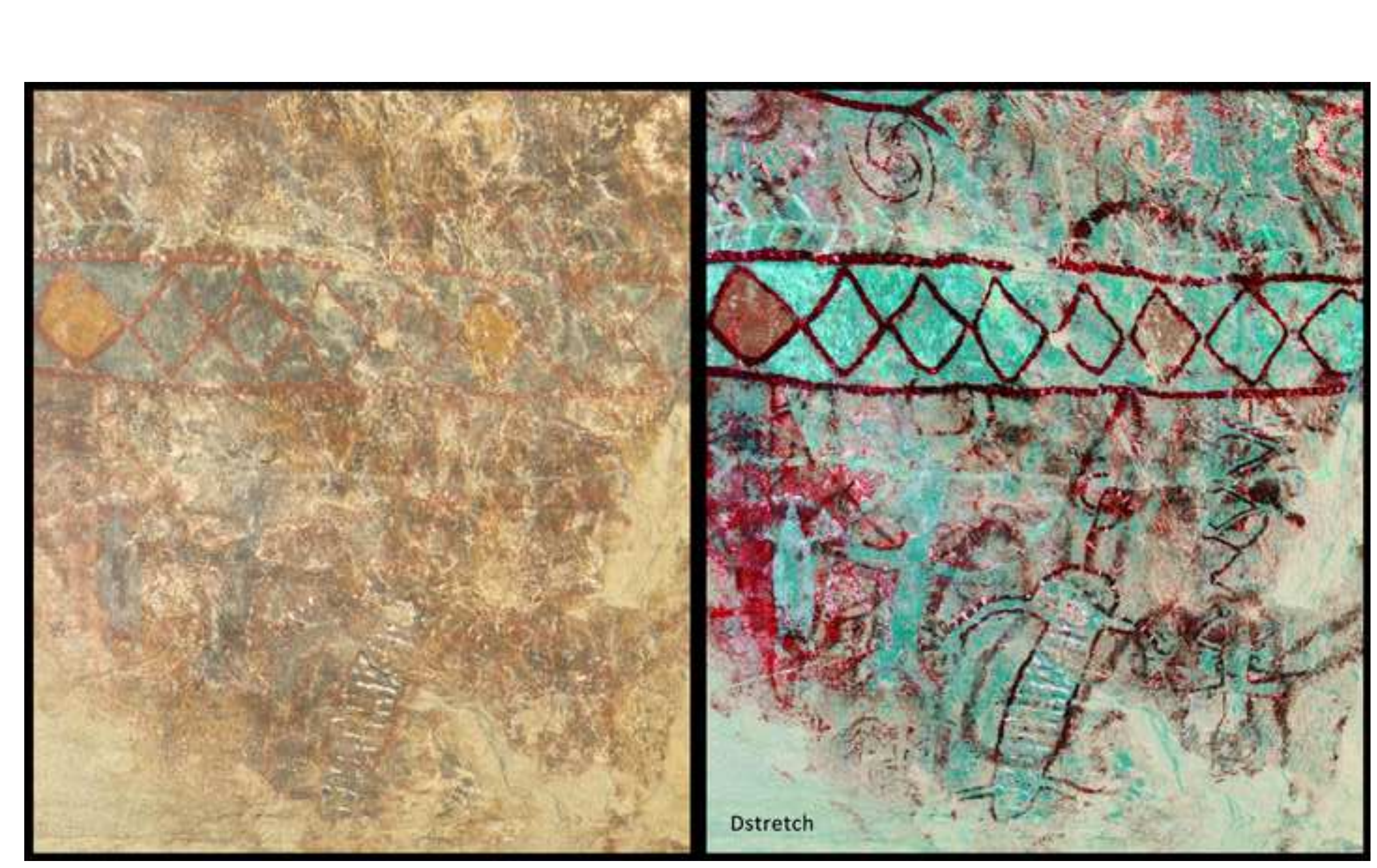


Click here to download high resolution image

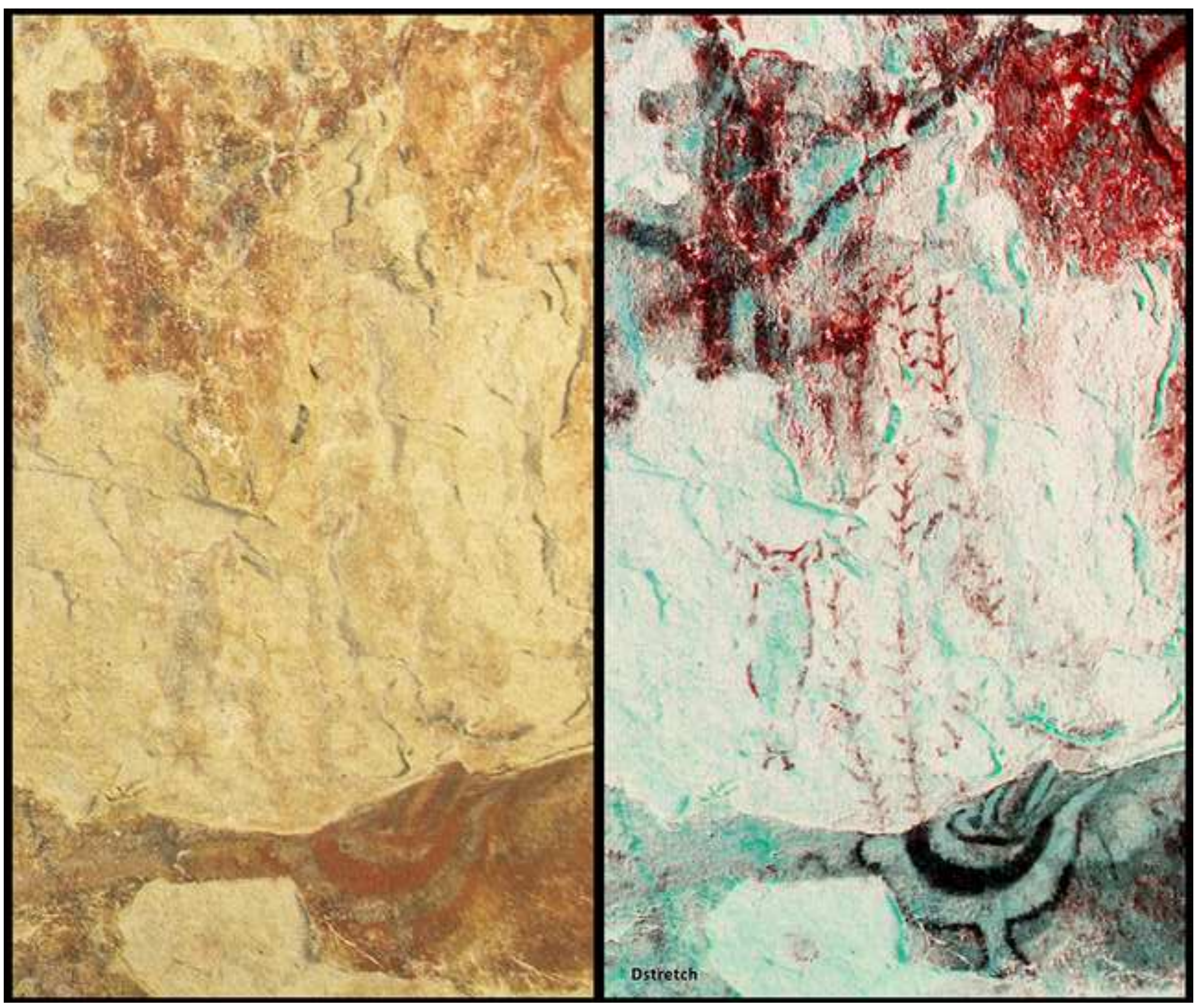


Click here to download high resolution image

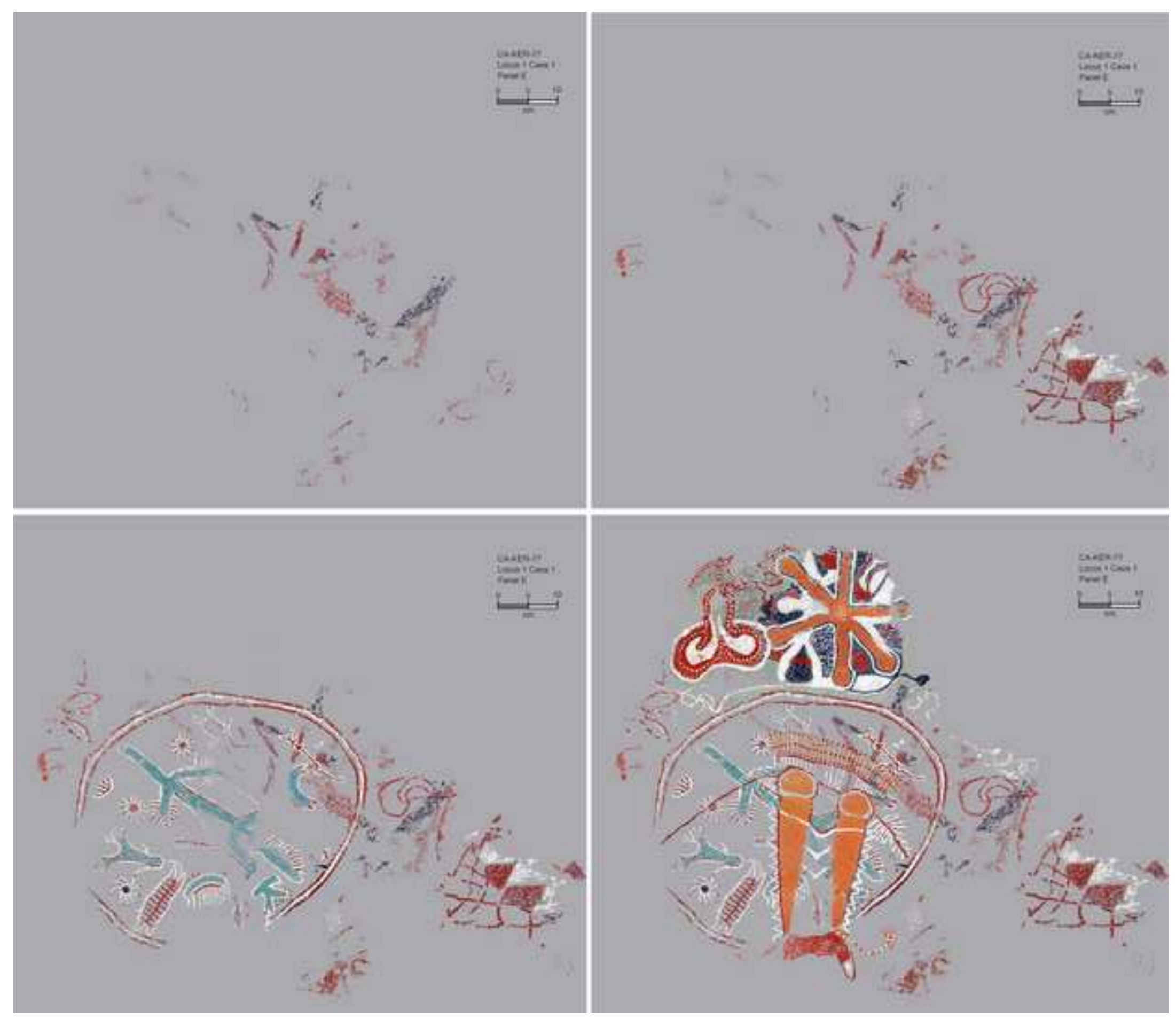


Click here to download high resolution image
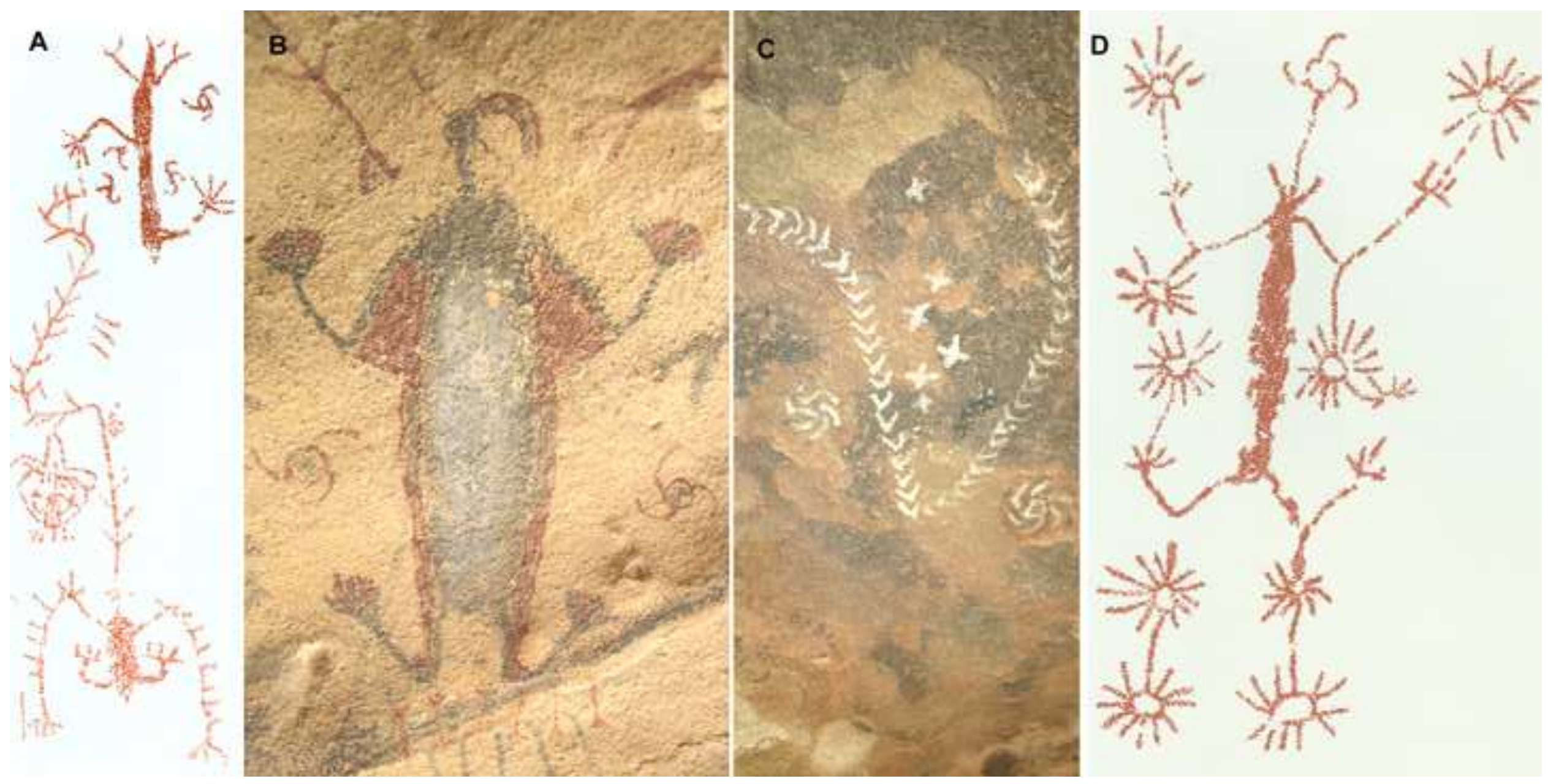
Click here to download high resolution image

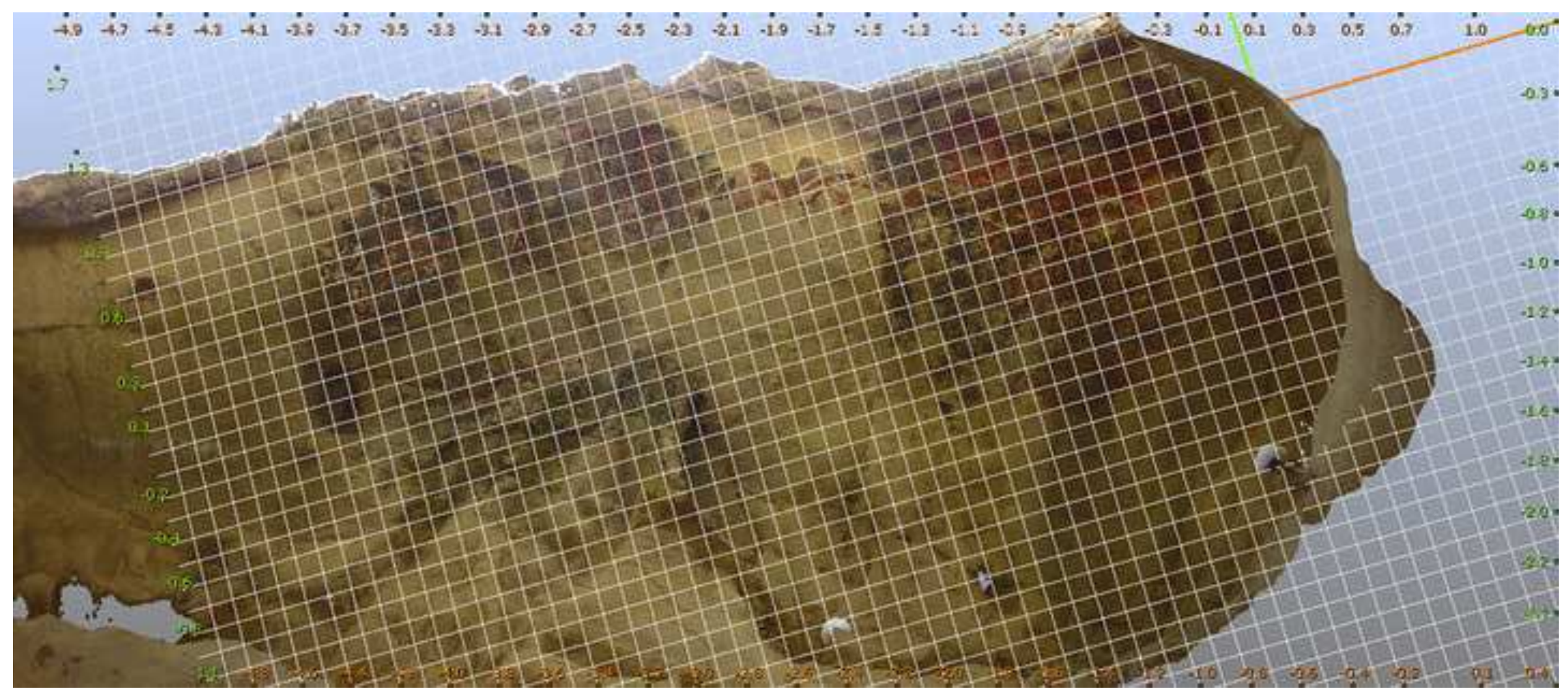


Click here to download high resolution image

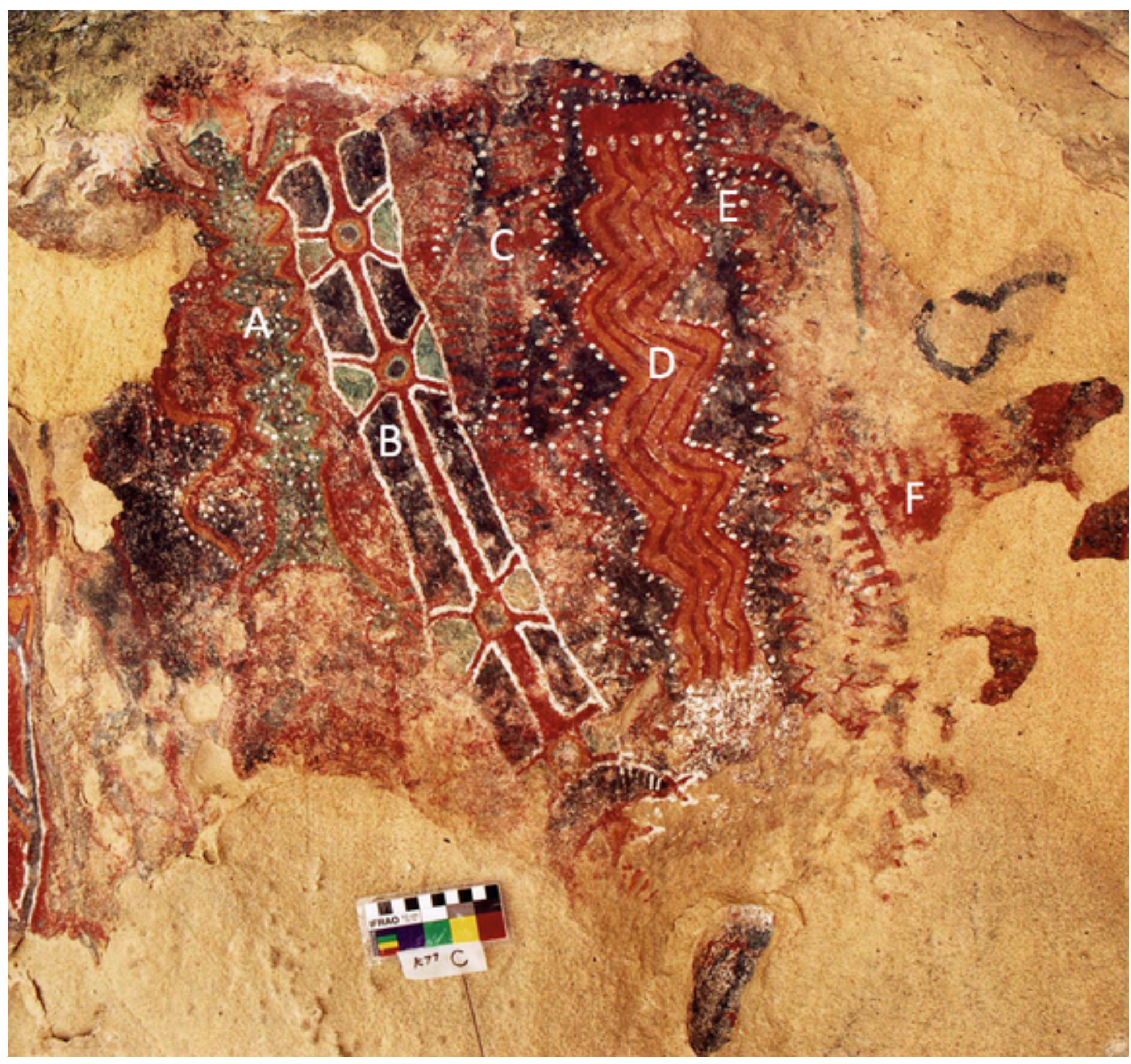


Click here to download high resolution image

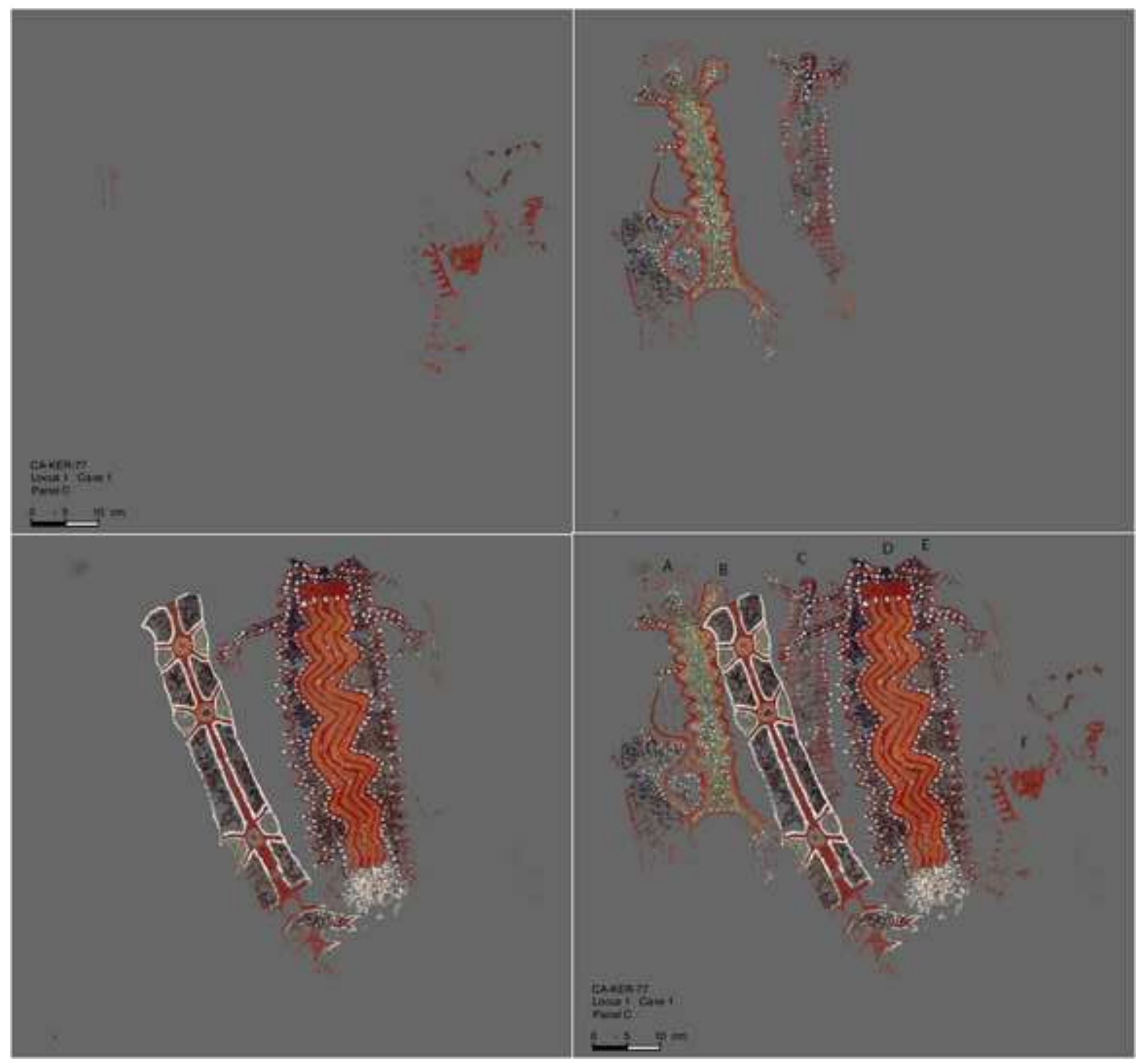
. 
Click here to download high resolution image

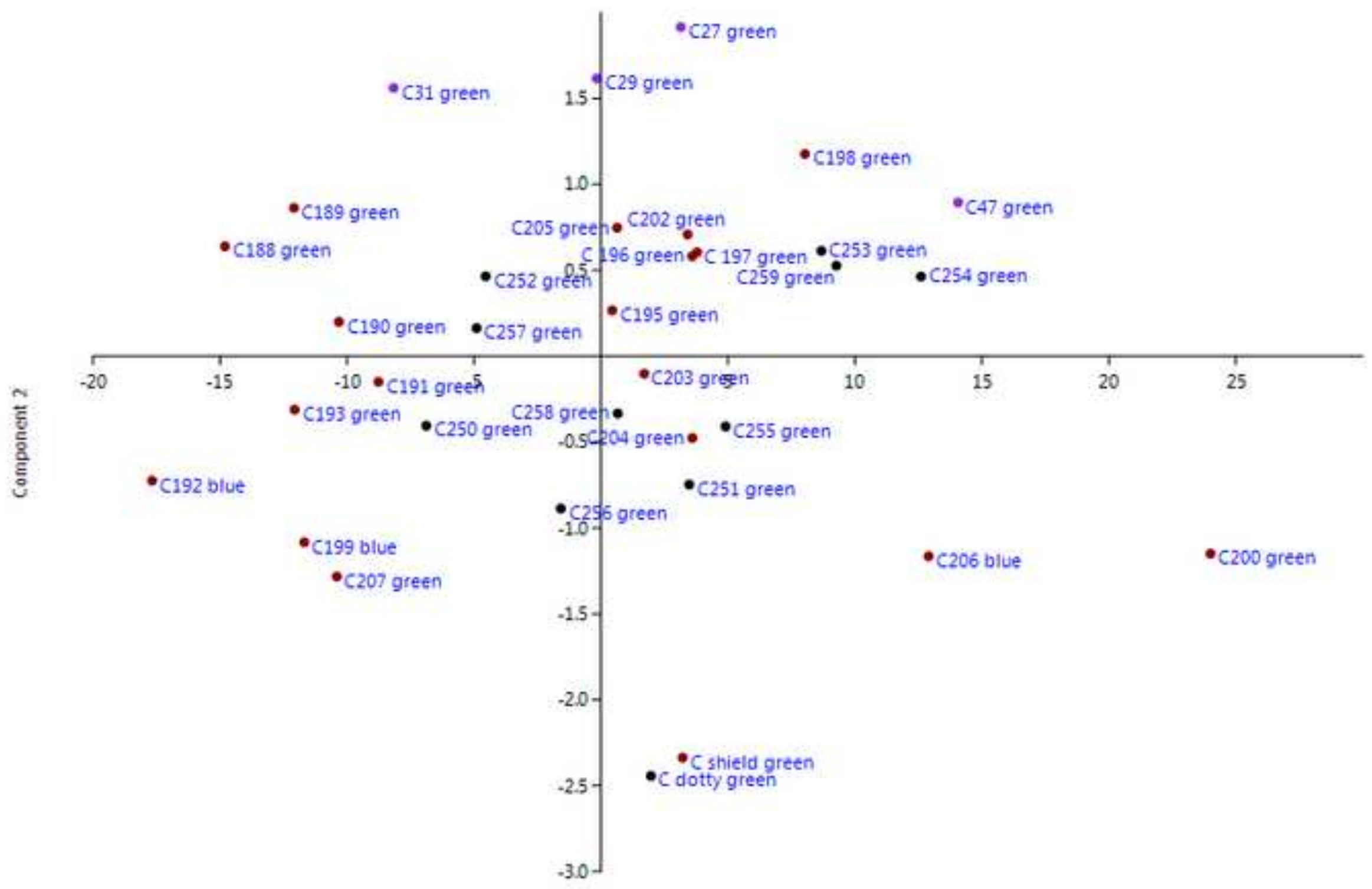

Component 1 
Click here to download high resolution image

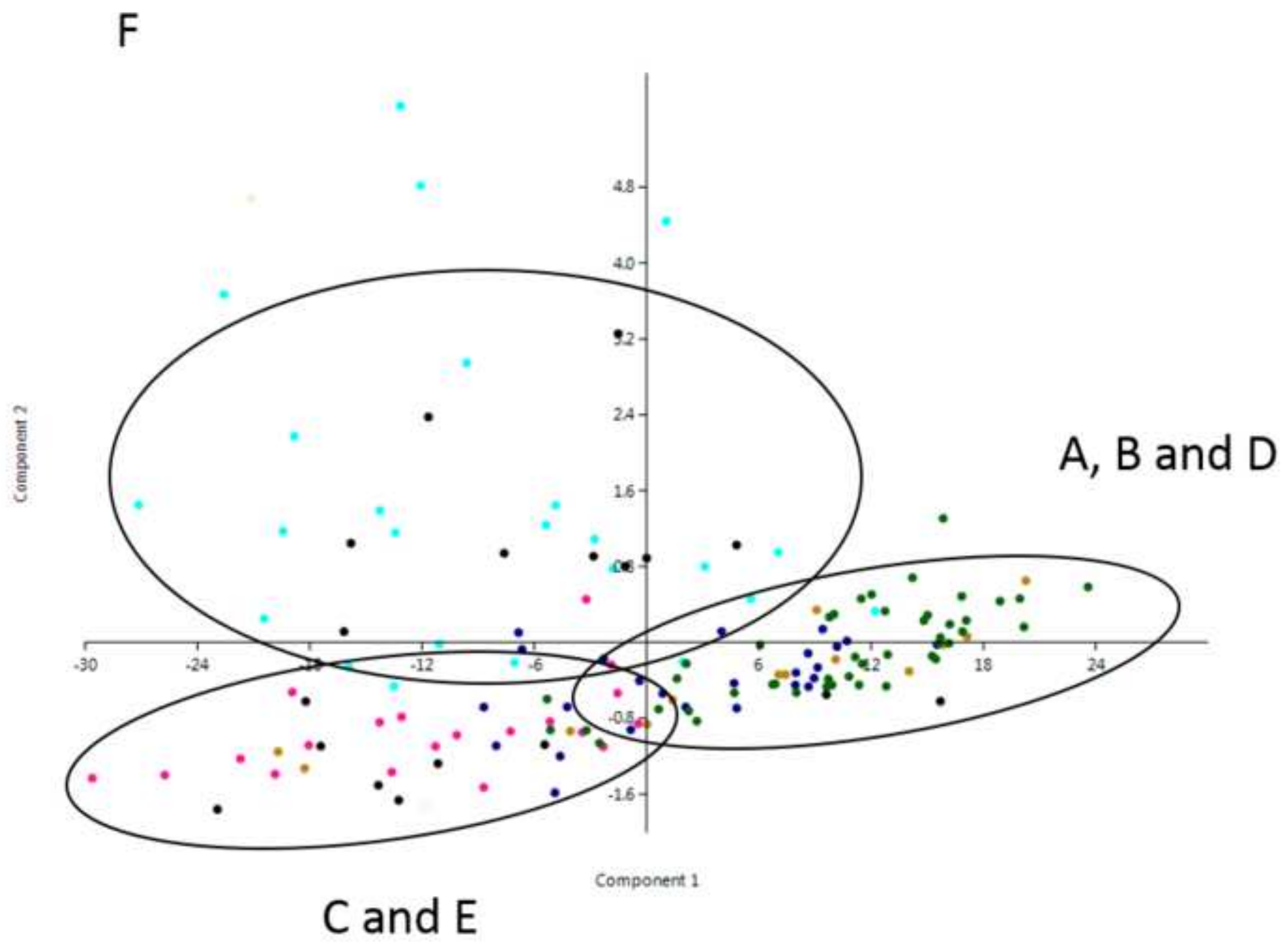


Click here to download high resolution image

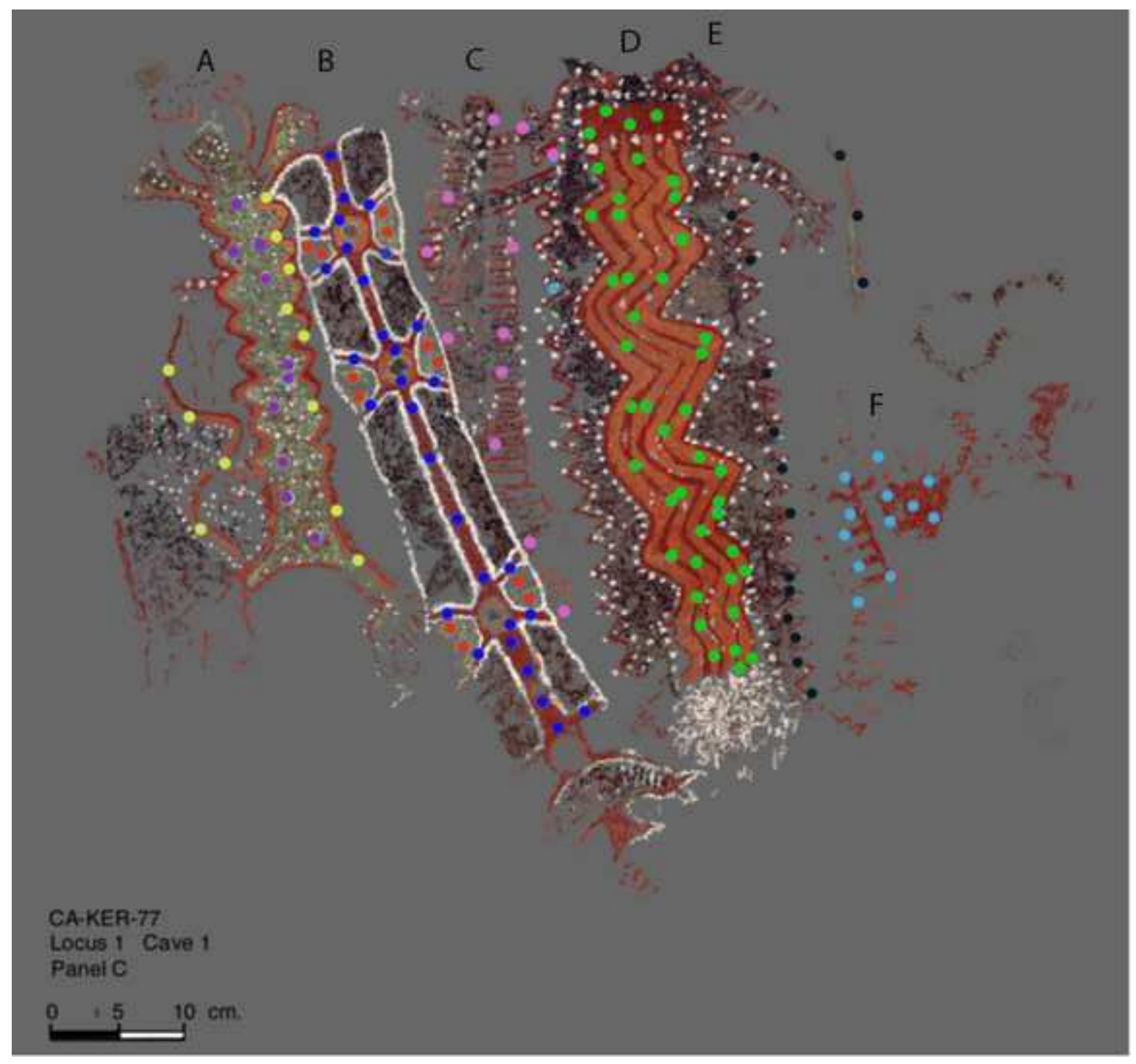


Click here to download high resolution image

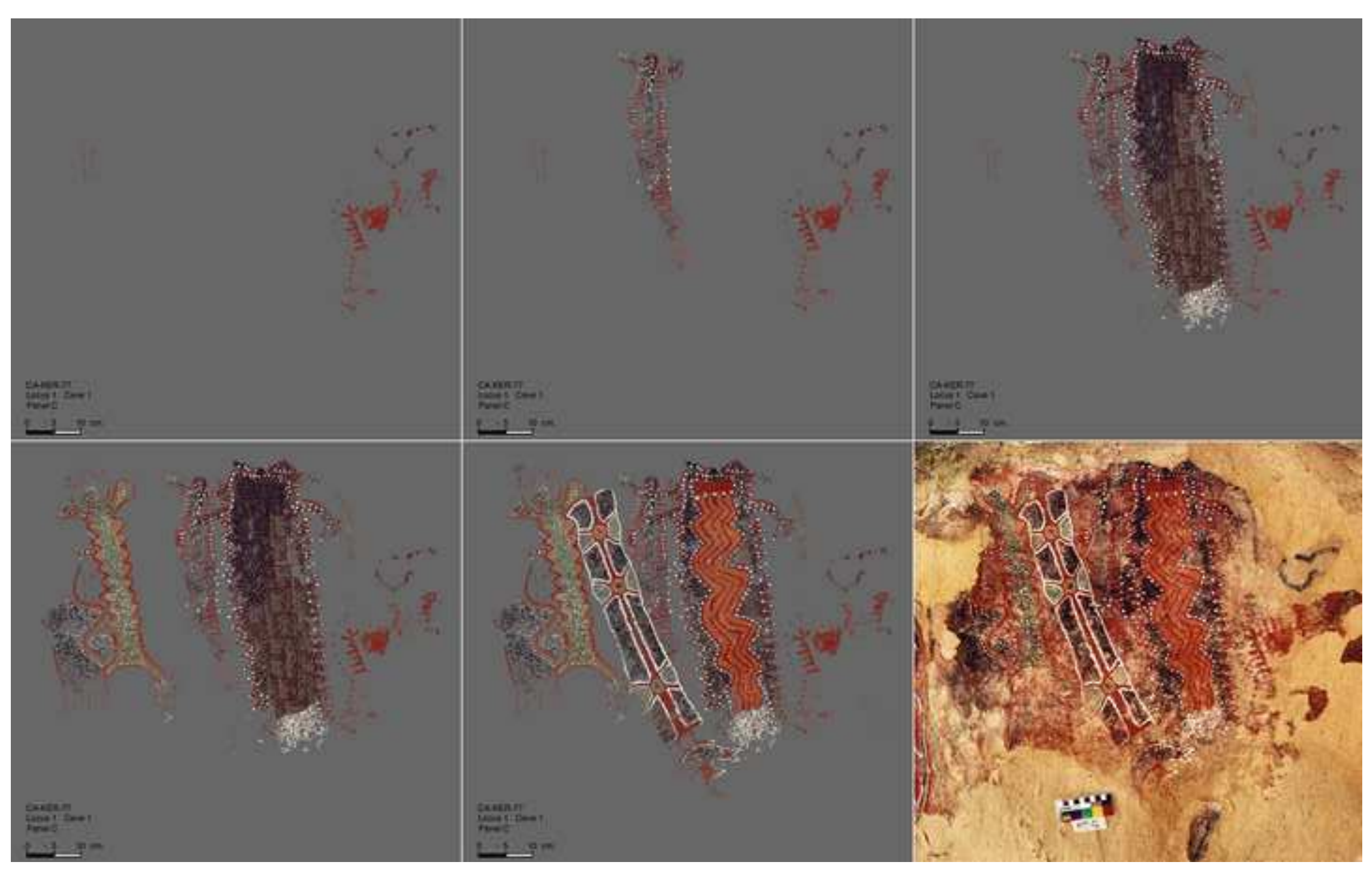


Figure 19
Click here to download high resolution image

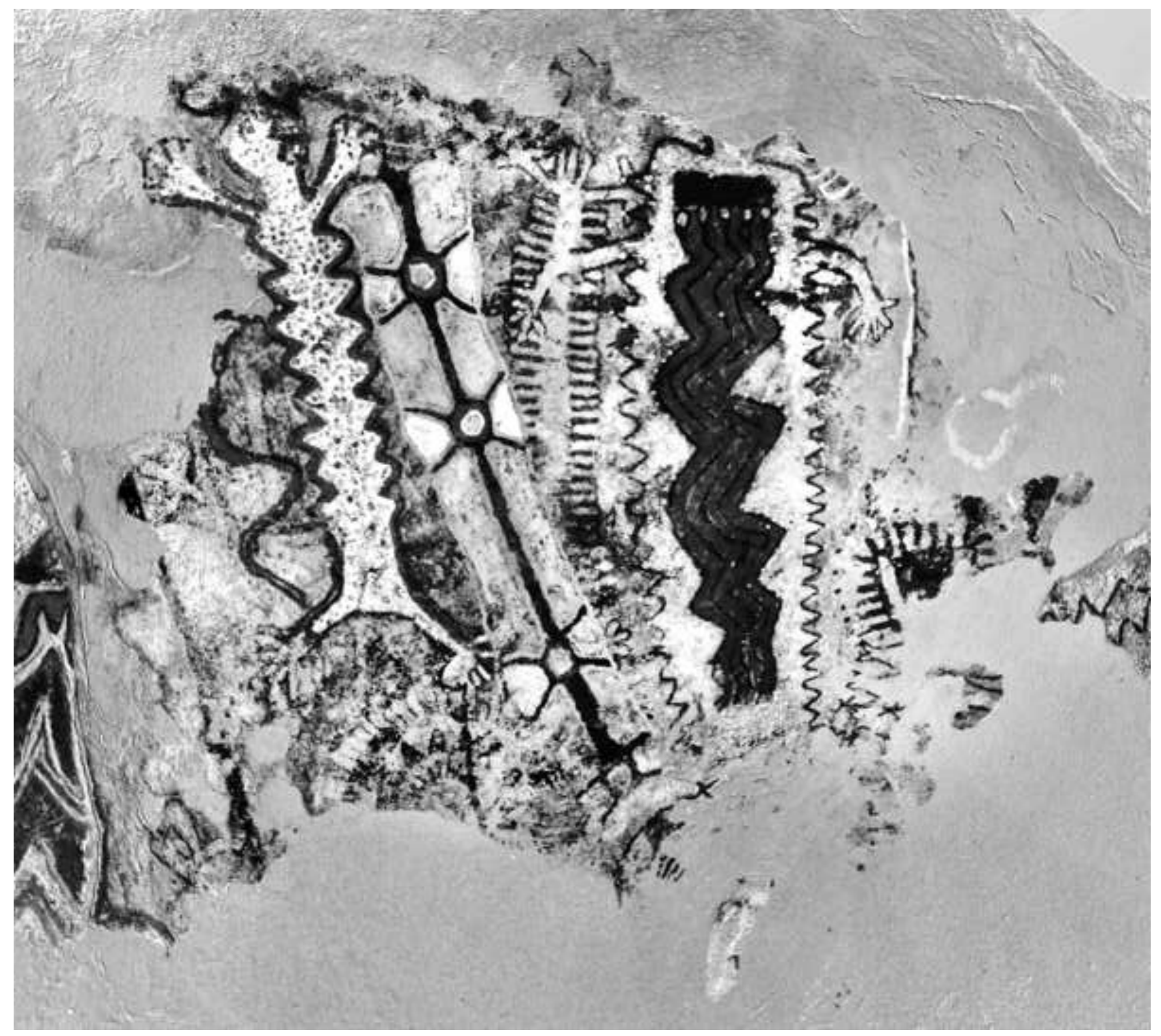


Figure 21
Click here to download high resolution image

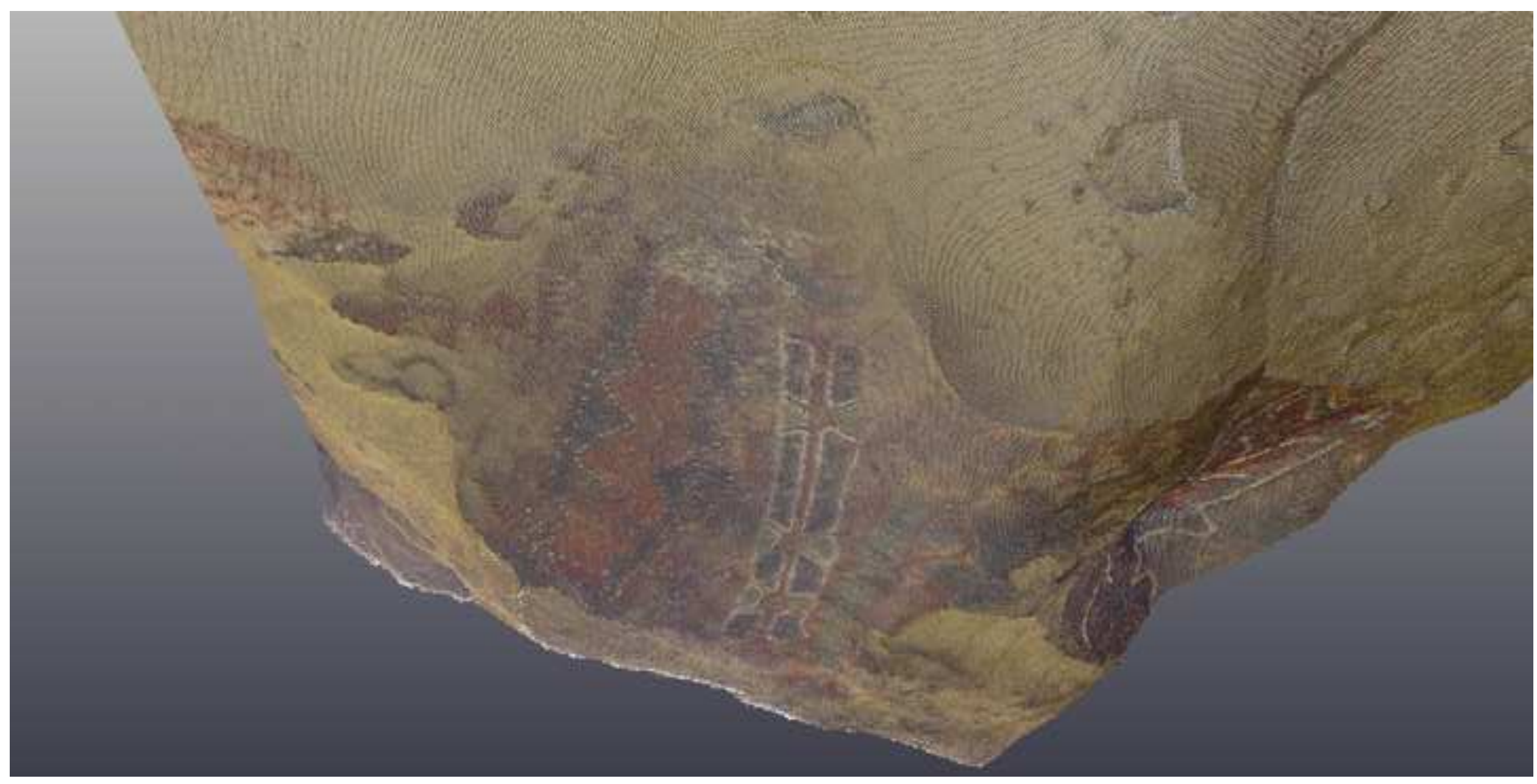


Video
Click here to download Video: Animation of the laser scan model of the Main Cave at Pleito.mp4

Video
Click here to download Video: Animation of the laser scan model of the Main Cave at Pleito.mp 4

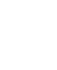

\section{4}

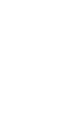

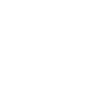

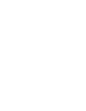
. .

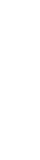

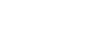

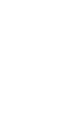

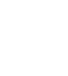

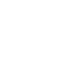

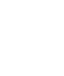

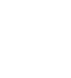

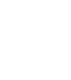

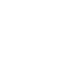

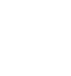

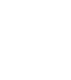

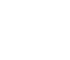




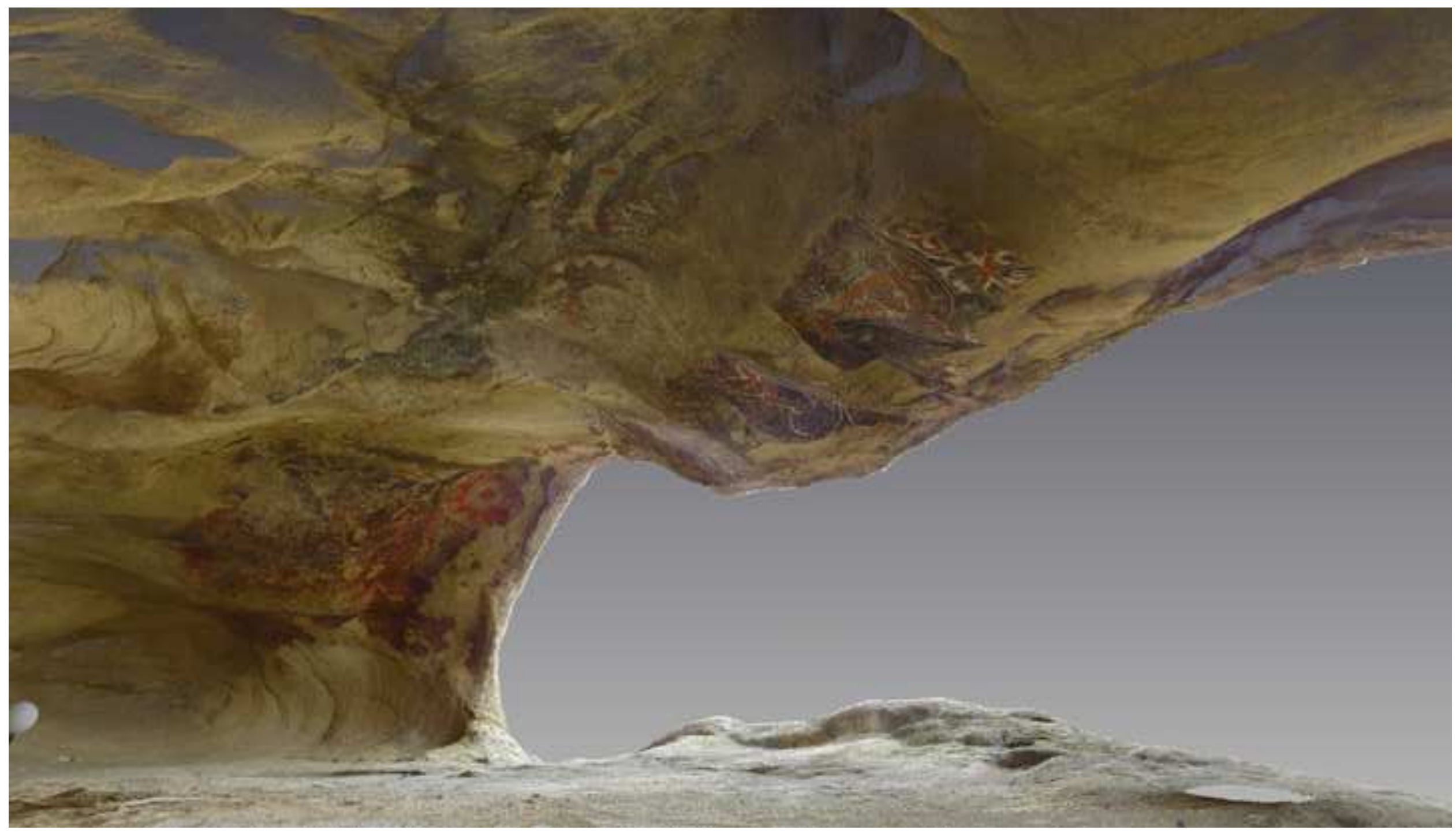

